\title{
Performance Analysis of Lossy Decode-and-Forward for Non-Orthogonal MARCs
}

\author{
Jiguang He, Student Member, IEEE, Valtteri Tervo, Member, IEEE, Shen Qian, Student Member, IEEE, \\ Qiang Xue, Markku Juntti, Senior Member, IEEE, and Tad Matsumoto, Fellow, IEEE,
}

\begin{abstract}
Non-orthogonal transmission is considered to be one of the promising techniques for improving the throughput of the existing and future wireless communication networks. We concentrate on the transmission of both independent and correlated binary sources over a non-orthogonal multiple access relay channel (MARC), which consists of two sources, one relay, and one destination. The lossy decode-and-forward (DF), developed from the conventional DF, is adopted at the relay. Two time slots are required with non-orthogonal transmission over such network setup, while three time slots are required with the conventional orthogonal transmission. We analyze the outage probability of transmission of independent binary sources over the non-orthogonal MARC based on the theorem of multiple access channel (MAC) with a helper, which combines the SlepianWolf rate region and the MAC capacity region. For the performance verification, we implement a practical coding-decoding chain, which is applicable to the transmission of both independent and correlated binary sources. Exclusive-OR (XOR) based multiuser complete decoding is introduced at the relay node, and iterative joint decoding is utilized at the destination by taking into consideration the estimated intra-link error probability and correlation information between the sources. The practical simulation results are well matched with the theoretical analyses.
\end{abstract}

Index Terms-Multiple access channel with a helper, multiple access relay channels, outage probability, Slepian-Wolf theorem, Shannon's lossy source-channel separation theorem.

\section{INTRODUCTION}

Cooperation among nodes in wireless cooperative networks is of great importance as it has great potential for achieving diversity gain, enhancing network throughput, and extending communication coverage even with a single antenna at each

This work has been performed in the framework of the FP7 project ICT-619555 RESCUE (Links on-the-fly Technology for Robust, Efficient and Smart Communication in Unpredictable Environments), which is partly funded by the European Union. This work is partially supported by the network compression based wireless cooperative communication systems (NETCOBRA, No. 268209) project, funded by the Academy of Finland. This work is also partially supported by Nokia Foundation, HPY Foundation, Oulu University Scholarship, and Riitta Ja Jorma J. Takanen Foundation Sr. The materials in this paper have been presented in part at the International Symposium on Turbo Codes \& Iterative Information Processing Conference, September, 2016

J. He, Q. Xue, and M. Juntti are with the Centre for Wireless Communications, University of Oulu, Oulu, 90014, Finland (e-mail: jiguang.he@oulu.fi, qiang.xue@oulu.fi, and markku.juntti@oulu.fi).

V. Tervo was with the Centre for Wireless Communications, University of Oulu, Oulu, 90014, Finland. He is now with Nokia Solutions and Networks, Espoo, Finland (email: valtteri.tervo@ nokia.com).

S. Qian and T. Matsumoto are with the school of Information Science, Japan Advanced Institute of Science and Technology (JAIST), Ishikawa, 9231292, Japan, and the Centre for Wireless Communications, University of Oulu, Oulu, 90014, Finland (e-mail: shen.qian@jaist.ac.jp, matumoto@jaist.ac.jp). node. Several simplified cooperative network models have been proposed in [1]-[10]. Besides the one-way relay channel (OWRC) [1]-[3] and the two-way relay channel (TWRC) [4], [5], the multiple access relay channel (MARC) is also one common wireless cooperative network and has been thoroughly investigated in [6]-[10]. The outage probability of the MARC has been formulated under the assumption of orthogonal transmission and perfect (error-free) intra links (i.e., source-to-relay links) [6]. Lu et al [8] has further relaxed the assumption of error-free intra links, and re-formulated the framework for outage probability analyses. Practical joint network-channel coding (JNCC) schemes have been investigated in [9]-[11] over MARC using different channel codes, for instance, low-density parity-check (LDPC) codes [9], accumulator (ACC) aided turbo codes [10], and more generic turbo code structure [11]. However, orthogonal transmission is postulated in all the aforementioned literature.

Due to the low spectral-efficiency of the orthogonal transmission, non-orthogonal transmission has attracted a lot of attention, for instance, in coded random access techniques [12], [13]. The non-orthogonal transmissions of the uncoordinated sets of sources lead to collisions. However, the collided packets can be utilized at the destination after multi-user detection (MUD), e.g., successive interference cancellation (SIC). By allowing non-orthogonal transmissions, higher throughput can be guaranteed, which is commonly seen in machine-tomachine (M2M) communications. Similarly, the same principle can be applied to non-orthogonal transmissions of the coordinated sets of sources. The transmission of correlated sources over non-orthogonal Gaussian multiple access channel (MAC) has been investigated in [14]. The extension to the transmission of correlated sources over non-orthogonal fading MAC has been investigated in [15]. A preliminary study on the transmission of correlated sources over non-orthogonal MARC can be found in [16], where no performance verification is provided by taking into account the helper ${ }^{1}$. In the MARC, the relay decodes the original information sequences, performs network coding (e.g., bit-wise exclusive-OR (XOR)), and forwards the network-coded sequence to the destination [7], [8]. This process at the relay is referred to as XOR based multi-user complete decoding (MUD-XOR) [17]-[19]. At the destination, joint decoding is conducted by taking into consideration the

\footnotetext{
${ }^{1}$ Note that the paper is an extension of [16]. However, the theoretical performance analyses are not exactly the same as those conducted in [16]. We use the MAC capacity region to characterize the first MAC transmission in the paper, while in [16] we built a virtual point-to-point channel for the first MAC transmission.
} 
correlation information between the two sources and the side information ${ }^{2}$ from the relay.

The relaying protocols, e.g., amplify-and-forward (AF), compress-and-forward (CF), and decode-and-forward (DF), have been well studied in [20]-[24]. In AF, the relay just amplifies the signal sent from the source and forwards it to the destination. The drawback of AF lies in that the signal and noise are amplified simultaneously, and the noise components are accumulated, hop by hop. Thus, it does not achieve good performance, especially in the low signal-to-noise ratio (SNR) regime [23]. Due to the additional processing at the relay, $\mathrm{CF}$ outperforms AF in general, for instance, in OWRC [23]. In DF, the relay first decodes the received signal, and then encodes and forwards it to the destination if no errors are found in the decoded information sequence. In fact, the erroneous decoded information sequence is correlated with the original information sequence from the source, i.e., it contains useful information, which can be utilized at the destination. Even though DF has the aforementioned drawback, it has been already applied in the current LTE-A cellular system [25] due to its robustness, implementation simplicity, and applicability to existing standards.

However, for the purpose of further improving the performance and reducing latency, an enhanced version of DF called lossy DF (also called lossy forward (LF)) has been investigated in [6], [8], [10], [26], where at the relay, the received signal from the source is decoded, re-encoded, and always forwarded to the destination. Thus, error-detecting codes, e.g., cyclic redundancy check (CRC), can be removed from the relay compared to its DF counterpart, resulting in a simpler transmission mechanism at the relay. Moreover, without additional power consumption at the source, better performance in terms of outage probability can be achieved compared to DF relaying [6], [8], [10], [26].

In the paper, we apply the LF relaying to the non-orthogonal MARC, study the theoretical performance limits for the LFMARC network, and compare the theoretical results with a series of simulation results, obtained by using practical coding and joint decoding algorithms. The main contributions of the paper are listed as follows:

- With the aim of eliminating the assumption of transmission orthogonality presented in [6]-[8], we focus on the transmissions over the non-orthogonal MARC. We analyze the outage probability for the transmission of independent binary sources over non-orthogonal MARC, where we establish a relationship among the transmit powers, geometric gains, and the distortion for the MAC composed of source-to-relay links.

- The outage probability for the transmission of independent binary sources over non-orthogonal MARC is derived by combining the non-orthogonal MAC consisting of source-to-destination links and the helper (i.e., network-coded version of the estimates of the two sources) from the relay. Due to the side information provided by the helper, the independent sources become

\footnotetext{
${ }^{2}$ The term "side information" is interchangeable with the term "helper" throughout the paper.
}

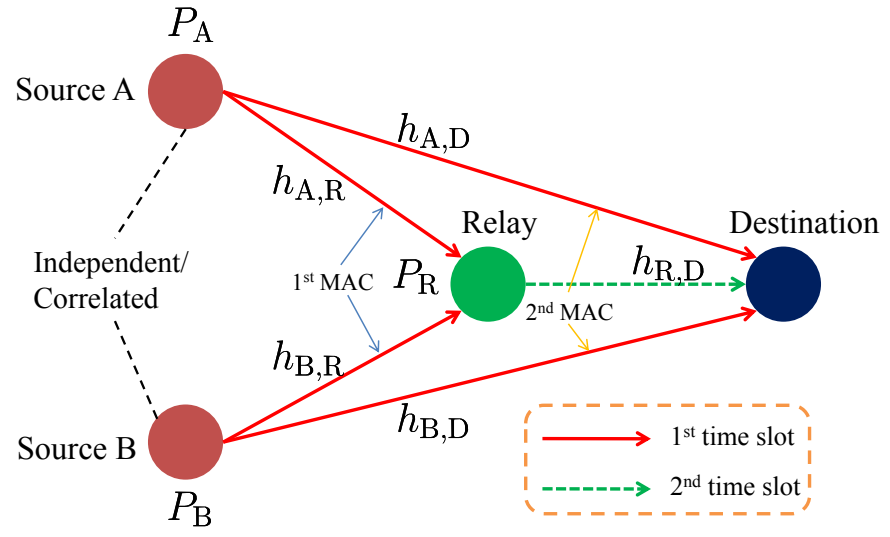

Figure 1. The block diagram of the non-orthogonal MARC with the application of LF relaying strategy.

virtually correlated at the destination. We characterize the source coding using Slepian-Wolf theorem and channel coding using MAC capacity region. The region for lossless transmission over the non-orthogonal MAC with a helper is specified by the intersection of the Slepian-Wolf rate region and the MAC capacity region. Outage occurs if the rate pair falls outside the intersection part [27], [28]. Since the outage derivation is based on sufficient condition for the lossless transmission over the nonorthogonal MAC with a helper (through independent design of the source and channel codes), the obtained intersection region might be smaller than that derived from the sufficient and necessary conditions. Hence, the outage performance we obtain can be regarded as a theoretical upper bound. In other words, we provide a safer side network design reference.

- A practical coding-decoding structure is introduced with the applicability to the transmission of both independent and correlated binary sources over the non-orthogonal MARC. ACC aided turbo code having a simple structure is applied in the encoding process. A joint iterative decoding scheme is proposed by considering the error probability of the intra links and the correlation information between the two sources, which are estimated at the destination during each global iteration (GI), i.e., iterations among different decoders. The extrinsic loglikelihood ratio (LLR) information is exchanged among the different convolutional decoders (two for the sources, and one for the relay) and between the ACC decoders of the sources.

The remainder of this paper is organized as follows. The system model is outlined in Section II. In Section III, theoretical outage probabilities are derived, followed by the performance verification using practical coding-decoding chain in Section IV. Simulation results are presented in Section V. Finally, concluding remarks and future work are provided in Section VI. 


\section{SYSTEM MODEL}

The non-orthogonal MARC is shown in Fig. 1, which has a symmetric topology. It consists of two sources (i.e., sources A and B), one relay (R), and one destination (D). Each node is assumed to be equipped with a single antenna and operated in a half-duplex mode. We further assume no cooperation between the sources except for transmission timing control. The transmission round is divided into two time slots as compared to three time slots consumption in the conventional orthogonal MARC $^{3}$. The binary information sequences generated from sources A and B are encoded, modulated, and simultaneously transmitted to the relay and the destination during the first time slot. The relay decodes both the source messages, performs bit-wise XOR, re-encodes, and forwards the XORed message to the destination during the second time slot.

Let the encoded and modulated symbol sequences of sources $\mathrm{A}$ and $\mathrm{B}$ be denoted by vectors $\mathrm{x}_{\mathrm{A}}$ and $\mathrm{x}_{\mathrm{B}}$, respectively. For the sake of convenience, we assume that each symbol has unit average power, i.e., $E\left\{\left|x_{\mathrm{A}}^{k}\right|^{2}\right\}=E\left\{\left|x_{\mathrm{B}}^{k}\right|^{2}\right\}=1$ for $k=1, \ldots, N$, where $x_{\mathrm{A}}^{k}$ and $x_{\mathrm{B}}^{k}$ are the $k$ th entry of $\mathbf{x}_{\mathrm{A}}$ and $\mathbf{x}_{\mathrm{B}}$, respectively, and $N$ is the dimension of $\mathbf{x}_{\mathrm{A}}$ and $\mathrm{x}_{\mathrm{B}}$. The received signal at the relay and destination during the first time-slot transmission can be expressed as

$$
\begin{aligned}
& \mathbf{y}_{\mathrm{R}, 1}=\sqrt{P_{\mathrm{A}} G_{\mathrm{A}, \mathrm{R}}} h_{\mathrm{A}, \mathrm{R}} \mathbf{x}_{\mathrm{A}}+\sqrt{P_{\mathrm{B}} G_{\mathrm{B}, \mathrm{R}}} h_{\mathrm{B}, \mathrm{R}} \mathbf{x}_{\mathrm{B}}+\mathbf{n}_{\mathrm{R}, 1}, \\
& \mathbf{y}_{\mathrm{D}, 1}=\sqrt{P_{\mathrm{A}} G_{\mathrm{A}, \mathrm{D}}} h_{\mathrm{A}, \mathrm{D}} \mathbf{x}_{\mathrm{A}}+\sqrt{P_{\mathrm{B}} G_{\mathrm{B}, \mathrm{D}}} h_{\mathrm{B}, \mathrm{D}} \mathbf{x}_{\mathrm{B}}+\mathbf{n}_{\mathrm{D}, 1},
\end{aligned}
$$

where all the wireless links suffer from independent and identically distributed (i.i.d.) Rayleigh block fading, distributed as $h_{\mathrm{A}, \mathrm{R}}, h_{\mathrm{B}, \mathrm{R}}, h_{\mathrm{A}, \mathrm{D}}, h_{\mathrm{B}, \mathrm{D}} \sim \mathcal{C} \mathcal{N}(0,1), P_{i}$ is the transmit power at source $i$, for $i \in\{\mathrm{A}, \mathrm{B}\}, G_{i, j}$ is the geometric gain between $i$ and $j$, for $i \in\{\mathrm{A}, \mathrm{B}\}$ and $j \in\{\mathrm{R}, \mathrm{D}\}$. For the purpose of simplicity, we set $G_{\mathrm{A}, \mathrm{D}}=G_{\mathrm{B}, \mathrm{D}}=1$. Each entry of additive white Gaussian noise (AWGN) vector $\mathbf{n}_{j, 1}$ also follows $\mathcal{C N}(0,1)$, for $j \in\{\mathrm{R}, \mathrm{D}\}$. The instantaneous individual received $\mathrm{SNR}$ can be written by

$$
\gamma_{i, j}=G_{i, j} P_{i}\left|h_{i, j}\right|^{2}, \text { for } i \in\{\mathrm{A}, \mathrm{B}\} \text { and } j \in\{\mathrm{R}, \mathrm{D}\},
$$

where $\left|h_{i, j}\right|^{2}$ follows exponential distribution with unit mean and unit variance. In this regard, the average SNR $\bar{\gamma}_{i, j}$ is expressed as $\bar{\gamma}_{i, j}=G_{i, j} P_{i}$. The probability density function (pdf) of $\gamma_{i, j}$ can be expressed as

$$
\begin{aligned}
& p\left(\gamma_{i, j}\right)=\frac{1}{P_{i} G_{i, j}} \exp \left(-\frac{\gamma_{i, j}}{P_{i} G_{i, j}}\right), \\
& \text { for } i \in\{\mathrm{A}, \mathrm{B}\} \text { and } j \in\{\mathrm{R}, \mathrm{D}\} .
\end{aligned}
$$

Because the relay is not interested in the original information sequences sent from the sources, the relay first executes MUD and then conducts bit-wise XOR on the estimates of the information sequences transmitted from sources A and B. This process is regarded as MUD-XOR. Regardless of whether the estimates are correct or not, the relay re-encodes and modulates the XORed version of the estimates to $\mathbf{x}_{\mathrm{R}}$, and

\footnotetext{
${ }^{3}$ In the conventional orthogonal MARC, source A broadcasts its message to the relay and destination during the first time slot. Source B becomes active during the second time slot and behaves the same as source A. During the third time slot, the relay decodes both the source messages, performs bit-wise XOR, re-encodes, and forwards the XORed message to the destination.
}

forwards it to the destination during the second time slot ${ }^{4}$ according to LF strategy. The received signal at the destination during the second time-slot transmission is given by

$$
\mathbf{y}_{\mathrm{D}, 2}=\sqrt{P_{\mathrm{R}} G_{\mathrm{R}, \mathrm{D}}} h_{\mathrm{R}, \mathrm{D}} \mathbf{x}_{\mathrm{R}}+\mathbf{n}_{\mathrm{D}, 2}
$$

where $P_{\mathrm{R}}$ denotes the transmit power at the relay, $h_{\mathrm{R}, \mathrm{D}}$ suffers from i.i.d. Rayleigh block fading, distributed as $h_{\mathrm{R}, \mathrm{D}} \sim$ $\mathcal{C N}(0,1)$, and each entry of $\mathbf{n}_{\mathrm{D}, 2}$ also follows $\mathcal{C N}(0,1)$. Without loss of generality, we set $P_{\mathrm{R}}=P_{\mathrm{A}}=P_{\mathrm{B}}=P$ throughout the paper.

\section{Theoretical Performance AnAlysis}

In this section, we assume that binary source $\mathrm{A}\left(U_{\mathrm{A}}\right)$ and binary source $\mathrm{B}\left(U_{\mathrm{B}}\right)$ are mutually independent, yielding $U_{\mathrm{A}}=U_{\mathrm{B}} \oplus U$ with $\operatorname{Pr}(U=0)=\operatorname{Pr}(U=1)=p_{u}=0.5$ and $\oplus$ denoting binary XOR operation. The theoretical performance analysis is divided into two parts, i.e., source-torelay transmission and source-to-destination transmission with side information transmitted from the relay. We characterize the source-to-relay transmission by using the MAC capacity region, and establish a relationship among the transmit powers, geometric gains, and the distortion. We characterize the source-to-destination transmission with side information by combining the Slepian-Wolf rate region and the MAC capacity region [27], [28], which is sufficient condition for the lossless transmission of independent binary sources over the nonorthogonal MAC with a helper. Therefore, the derived outage probability can be regarded as a theoretical upper bound.

\section{A. Source-to-Relay Transmission}

Obviously, the source-to-relay channel is a two-user MAC, which we define as the first MAC in Fig. 1. The capacity region for the source-to-relay MAC is a bounded pentagonal region [27], and the whole positive orthant is divided into four non-overlapping sub-regions, shown in Fig. 2. In the figure, $\mu_{\mathrm{A}, \mathrm{R}}=P G_{\mathrm{A}, \mathrm{R}}\left|h_{\mathrm{A}, \mathrm{R}}\right|^{2} /\left(1+P G_{\mathrm{B}, \mathrm{R}}\left|h_{\mathrm{B}, \mathrm{R}}\right|^{2}\right)$ and $\mu_{\mathrm{B}, \mathrm{R}}=$ $P G_{\mathrm{B}, \mathrm{R}}\left|h_{\mathrm{B}, \mathrm{R}}\right|^{2} /\left(1+P G_{\mathrm{A}, \mathrm{R}}\left|h_{\mathrm{A}, \mathrm{R}}\right|^{2}\right)$ denote the instantaneous signal-to-interference-plus-noise ratio (SINR) of source A and source $\mathrm{B}$, respectively, and $\mathrm{C}(a)=\log _{2}(1+a)$ denotes the capacity function under the assumption of Gaussian codebook.

When the rate pair of sources $\mathrm{A}$ and $\mathrm{B}$, i.e., $\left(R_{c, \mathrm{~A}}, R_{c, \mathrm{~B}}\right)^{5}$, falls in the region $\mathcal{R}_{4}$, both information sequences from the two sources can be recovered with arbitrarily small error probability at the relay. On the contrary, neither of the information sequences from the two sources can be successfully recovered when the rate pair falls in the region $\mathcal{R}_{3}$. When it comes to $\mathcal{R}_{1}$ and $\mathcal{R}_{2}$, only one of the information sequences can be perfectly recovered while the other probabilistically fails.

The probabilities that the rate pair $\left(R_{c, \mathrm{~A}}, R_{c, \mathrm{~B}}\right)$ falls into regions $\mathcal{R}_{1}$ to $\mathcal{R}_{4}$, i.e., $\operatorname{Pr}\left(\mathcal{R}_{1}\right)$ to $\operatorname{Pr}\left(\mathcal{R}_{4}\right)$, depend on the predetermined transmission rates, instantaneous received SNRs,

\footnotetext{
${ }^{4}$ Due to the application of lossy DF, the relay always becomes active during the second time slot. However, with the application of DF, the relay will be silent if errors are detected after the MUD either for source A or source B.

${ }^{5} R_{c, \mathrm{~A}}$ and $R_{c, \mathrm{~B}}$ are the multiplications of channel coding rate and modulation order, i.e., transmission rates, for the sources A and B, respectively.
} 


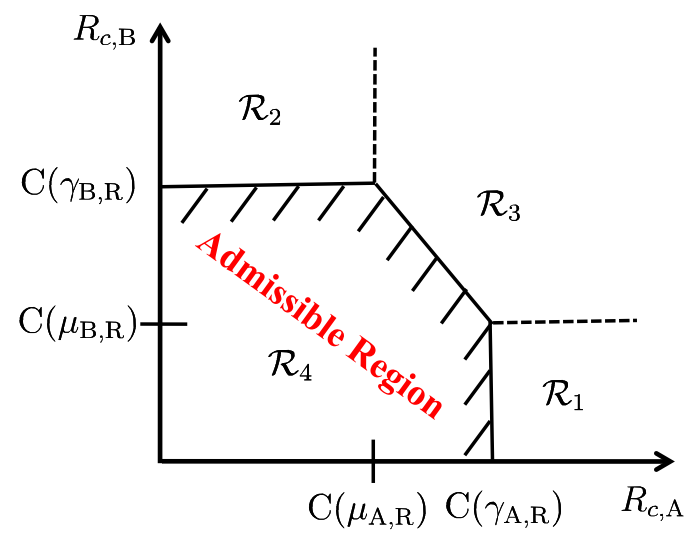

Figure 2. Rate region for source-to-relay transmission.

and instantaneous SINRs of sources A and B. They can be expressed as [29]

$\operatorname{Pr}\left(\mathcal{R}_{1}\right)=\operatorname{Pr}\left[R_{c, \mathrm{~A}}>\log _{2}\left(1+\gamma_{\mathrm{A}, \mathrm{R}}\right), R_{c, \mathrm{~B}} \leq \log _{2}\left(1+\frac{\gamma_{\mathrm{B}, \mathrm{R}}}{1+\gamma_{\mathrm{A}, \mathrm{R}}}\right)\right]$,

$\operatorname{Pr}\left(\mathcal{R}_{2}\right)=\operatorname{Pr}\left[R_{c, \mathrm{~A}} \leq \log _{2}\left(1+\frac{\gamma_{\mathrm{A}, \mathrm{R}}}{1+\gamma_{\mathrm{B}, \mathrm{R}}}\right), R_{c, \mathrm{~B}}>\log _{2}\left(1+\gamma_{\mathrm{B}, \mathrm{R}}\right)\right]$

$\operatorname{Pr}\left(\mathcal{R}_{3}\right)=\operatorname{Pr}\left[R_{c, \mathrm{~A}}>\log _{2}\left(1+\frac{\gamma_{\mathrm{A}, \mathrm{R}}}{1+\gamma_{\mathrm{B}, \mathrm{R}}}\right)\right.$,

$\left.R_{c, \mathrm{~B}}>\log _{2}\left(1+\frac{\gamma_{\mathrm{B}, \mathrm{R}}}{1+\gamma_{\mathrm{A}, \mathrm{R}}}\right), R_{c, \mathrm{~A}}+R_{c, \mathrm{~B}}>\log _{2}\left(1+\gamma_{\mathrm{A}, \mathrm{R}}+\gamma_{\mathrm{B}, \mathrm{R}}\right)\right]$

$\operatorname{Pr}\left(\mathcal{R}_{4}\right)=\operatorname{Pr}\left[R_{c, \mathrm{~A}}<\log _{2}\left(1+\frac{\gamma_{\mathrm{A}, \mathrm{R}}}{1+\gamma_{\mathrm{B}, \mathrm{R}}}\right), R_{c, \mathrm{~B}}<\log _{2}\left(1+\gamma_{\mathrm{B}, \mathrm{R}}\right)\right]$

$+\operatorname{Pr}\left[\log _{2}\left(1+\frac{\gamma_{\mathrm{A}, \mathrm{R}}}{1+\gamma_{\mathrm{B}, \mathrm{R}}}\right) \leq R_{c, \mathrm{~A}}<\log _{2}\left(1+\gamma_{\mathrm{A}, \mathrm{R}}\right)\right.$,

$\left.R_{c, \mathrm{~A}}+R_{c, \mathrm{~B}}<\log _{2}\left(1+\gamma_{\mathrm{A}, \mathrm{R}}+\gamma_{\mathrm{B}, \mathrm{R}}\right)\right]$.

When evaluating $\mathcal{R}_{1}$ and $\mathcal{R}_{2}$, after canceling the successfully decoded information sequence, the calculation of the distortion of the other information sequence becomes the same as that in a point-to-point ( $\mathrm{P} 2 \mathrm{P})$ transmission problem. Therefore, the distortion can be obtained by using the Shannon's lossy source-channel separation theorem [6], [10]. For instance, when the rate pair falls into $\mathcal{R}_{1}$, we have $\hat{U}_{\mathrm{A}} \neq U_{\mathrm{A}}$, $\hat{U}_{\mathrm{B}}=U_{\mathrm{B}}$ (For the other sub-regions, more details can be found in Table I) with $\hat{U}_{\mathrm{A}}, \hat{U}_{\mathrm{B}}$ being the estimates of $U_{\mathrm{A}}, U_{\mathrm{B}}$ at the relay. The distortion of $U_{\mathrm{A}}$, denoted by $D$, is determined by ${ }^{6}$

$$
R(D) R_{c, \mathrm{~A}} \leq C\left(\gamma_{\mathrm{A}, \mathrm{R}}\right)
$$

\footnotetext{
${ }^{6}$ More strictly, we should use the binary constellation constrained capacity (CCC) here. However, if the instantaneous SNR is low, the Gaussian capacity is almost equal to CCC [30]. If the instantaneous SNR is large, the distortion would be zero as long as the fixed transmission rate is less than the CCC. Hence, the use of the binary rate distortion function and the Gaussian capacity is reasonable when using the lossy source-channel separation theorem [1].
}

Table I

Relationship Between the Sub-Regions And the Decoding OUTCOMES AT THE RELAY.

\begin{tabular}{|l|l|}
\hline $\mathcal{R}_{1}$ & $\hat{U}_{\mathrm{A}} \neq U_{\mathrm{A}}, \hat{U}_{\mathrm{B}}=U_{\mathrm{B}}$ \\
\hline $\mathcal{R}_{2}$ & $\hat{U}_{\mathrm{A}}=U_{\mathrm{A}}, \hat{U}_{\mathrm{B}} \neq U_{\mathrm{B}}$ \\
\hline $\mathcal{R}_{3}$ & $\hat{U}_{\mathrm{A}} \neq U_{\mathrm{A}}, \hat{U}_{\mathrm{B}} \neq U_{\mathrm{B}}$ \\
\hline $\mathcal{R}_{4}$ & $\hat{U}_{\mathrm{A}}=U_{\mathrm{A}}, \hat{U}_{\mathrm{B}}=U_{\mathrm{B}}$ \\
\hline
\end{tabular}

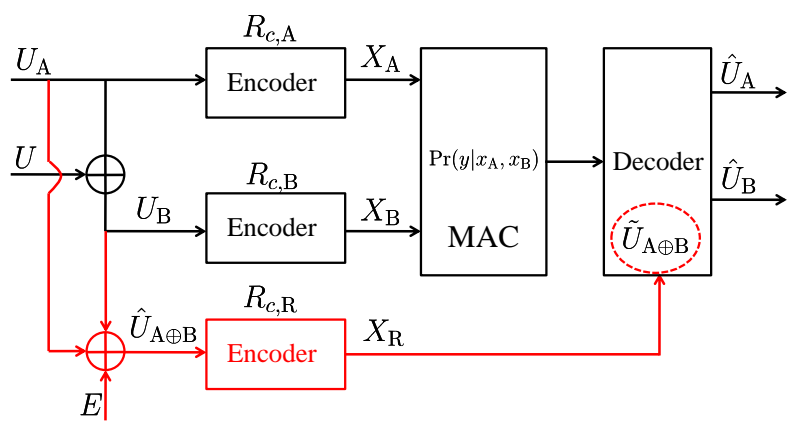

Figure 3. Illustration of MAC with a helper.

where $R(D)$ represents the binary rate distortion function. Setting $\Phi\left(\gamma_{\mathrm{A}, \mathrm{R}}\right)=C\left(\gamma_{\mathrm{A}, \mathrm{R}}\right) / R_{c, \mathrm{~A}}$, the calculation of the minimum distortion of $U_{\mathrm{A}}$, denoted by $D_{\min }$, can be further computed by [8]

$D_{\min }=\left\{\begin{array}{lc}H_{b}^{-1}\left[1-\Phi\left(\gamma_{\mathrm{A}, \mathrm{R}}\right)\right], & \text { for } \Phi^{-1}(0) \leq \gamma_{\mathrm{A}, \mathrm{R}} \leq \Phi^{-1}(1), \\ 0, & \text { for } \gamma_{\mathrm{A}, \mathrm{R}} \geq \Phi^{-1}(1),\end{array}\right.$

where $H_{b}(p)=-p \log _{2}(p)-(1-p) \log _{2}(1-p)$ denotes the binary entropy function, $H_{b}^{-1}(\cdot)$ denotes its inverse function, and $\Phi^{-1}(a)=2^{a R_{c, \mathrm{~A}}}-1$ is the inverse function of $\Phi(\cdot)$. The approximated closed-form expression of $H_{b}^{-1}(\cdot)$ is given in [1]. The relationship between the XORed version of the estimates $\hat{U}_{\mathrm{A} \oplus \mathrm{B}}=\hat{U}_{\mathrm{A}} \oplus \hat{U}_{\mathrm{B}}$ and its original one (denoted by $\left.U_{\mathrm{A} \oplus \mathrm{B}}=U_{\mathrm{A}} \oplus U_{\mathrm{B}}\right)$ can also be modeled by bit-flipping model with bit-flipping probability $p_{e}$,

$$
\hat{U}_{\mathrm{A} \oplus \mathrm{B}}=U_{\mathrm{A} \oplus \mathrm{B}} \oplus E,
$$

where $\operatorname{Pr}(E=1)=p_{e}$. Equation (12) can be further expressed as $\hat{U}_{\mathrm{A}}=U_{\mathrm{A}} \oplus E$. In this sense, we set $p_{e}=D_{\text {min }}$. We can calculate the distortion for $U_{\mathrm{B}}$ when the rate pair falls into $\mathcal{R}_{2}$ in the same manner.

We ignore $\mathcal{R}_{3}$ in the calculation of outage probability for the following two reasons: 1) If both sources are erroneous, the helper cannot improve the performance of the second MAC (see Fig. 1) consisting of source-to-destination links. 2) When the SNR increases, the probability of $\left(R_{c, \mathrm{~A}}, R_{c, \mathrm{~B}}\right)$ falling in $\mathcal{R}_{3}$ becomes very small. Therefore, the ratio of $\operatorname{Pr}\left\{\mathcal{R}_{3}\right\} / \sum_{i=1, i \neq 3}^{4} \operatorname{Pr}\left\{\mathcal{R}_{i}\right\}$ approaches zero in the high SNR regime.

\section{B. MAC with a Helper}

In the non-orthogonal MARC, the source-to-destination transmission during the first time slot combined with the relayto-destination transmission during the second time slot can 
be regarded as MAC with a helper, as shown in Fig. 3 . By the MAC definition [27], the MAC capacity region is determined by the channels involved in this equivalent MAC interpretation of the non-orthogonal MARC. In other words, it is not enlarged by the existence of the helper. The independent sources become effectively correlated at the destination due to the side information provided by the helper. The resulting rate region can be characterized by the Slepian-Wolf theorem. Therefore, for tractability, we take the intersection of the Slepian-Wolf rate region and the MAC capacity region into consideration to obtain the region for lossless recovery [27], [28]. This derivation is based on the sufficient condition for lossless transmission of independent sources over MAC with a helper.

The Slepian-Wolf rate region will be enlarged with the help of side information due to the fact that conditioning reduces entropy. More details are provided as follows.

The Slepian-Wolf rate region without the side information can be represented by

$$
\begin{aligned}
& R_{s, \mathrm{~A}} \geq H\left(U_{\mathrm{A}} \mid U_{\mathrm{B}}\right)=H_{b}\left(p_{u}\right)=1, \\
& R_{s, \mathrm{~B}} \geq H\left(U_{\mathrm{B}} \mid U_{\mathrm{A}}\right)=H_{b}\left(p_{u}\right)=1, \\
& R_{s, \mathrm{~A}}+R_{s, \mathrm{~B}} \geq H\left(U_{\mathrm{A}}, U_{\mathrm{B}}\right)=1+H_{b}\left(p_{u}\right)=2,
\end{aligned}
$$

where $R_{s, \mathrm{~A}}$ and $R_{s, \mathrm{~B}}$ are the rates of sources $\mathrm{A}$ and $\mathrm{B}$, respectively. With the aid of the helper, the Slepian-Wolf rate region will be enlarged as

$$
\begin{aligned}
R_{s, \mathrm{~A}} & \geq H\left(U_{\mathrm{A}} \mid U_{\mathrm{B}}, \tilde{U}_{\mathrm{A} \oplus \mathrm{B}}\right) \\
& =H_{b}\left(p_{e} * p_{d}\right), \\
R_{s, \mathrm{~B}} & \geq H\left(U_{\mathrm{B}} \mid U_{\mathrm{A}}, \tilde{U}_{\mathrm{A} \oplus \mathrm{B}}\right) \\
& =H_{b}\left(p_{e} * p_{d}\right), \\
R_{s, \mathrm{~A}}+R_{s, \mathrm{~B}} & \geq H\left(U_{\mathrm{A}}, U_{\mathrm{B}} \mid \tilde{U}_{\mathrm{A} \oplus \mathrm{B}}\right) \\
& =1+H_{b}\left(p_{e} * p_{d}\right),
\end{aligned}
$$

where $\tilde{U}_{\mathrm{A} \oplus \mathrm{B}}$ is the estimate of $\hat{U}_{\mathrm{A} \oplus \mathrm{B}}$ with bit-flipping probability $p_{d}$ at the destination and $a * b=a(1-b)+(1-a) b$. The relationship between $\tilde{U}_{\mathrm{A} \oplus \mathrm{B}}$ and $\hat{U}_{\mathrm{A} \oplus \mathrm{B}}$ can also be modeled by

$$
\tilde{U}_{\mathrm{A} \oplus \mathrm{B}}=\hat{U}_{\mathrm{A} \oplus \mathrm{B}} \oplus D
$$

where $\operatorname{Pr}(D=1)=p_{d}$. Similar to (11), $p_{d}$ can be calculated as

$$
p_{d}= \begin{cases}H_{b}^{-1}\left[1-\Phi\left(\gamma_{\mathrm{R}, \mathrm{D}}\right)\right], & \text { for } \Phi^{-1}(0) \leq \gamma_{\mathrm{R}, \mathrm{D}} \leq \Phi^{-1}(1), \\ 0, & \text { for } \gamma_{\mathrm{R}, \mathrm{D}} \geq \Phi^{-1}(1) .\end{cases}
$$

More details on the derivation of (16)-(18) can be found in Appendix A.

The MAC capacity region is determined by [28]

$$
\begin{aligned}
& R_{s, \mathrm{~A}} R_{c, \mathrm{~A}} \leq C\left(\gamma_{\mathrm{A}, \mathrm{D}}\right), \\
& R_{s, \mathrm{~B}} R_{c, \mathrm{~B}} \leq C\left(\gamma_{\mathrm{B}, \mathrm{D}}\right), \\
& R_{s, \mathrm{~A}} R_{c, \mathrm{~A}}+R_{s, \mathrm{~B}} R_{c, \mathrm{~B}} \leq C\left(\gamma_{\mathrm{A}, \mathrm{D}}+\gamma_{\mathrm{B}, \mathrm{D}}\right) .
\end{aligned}
$$

The region for lossless transmission of the two independent sources over the non-orthogonal MARC is the intersection part determined by (16)-(18) and (21)-(23).

An Example: Let us show an example to illustrate the region for lossless recovery for MAC with a helper. We set

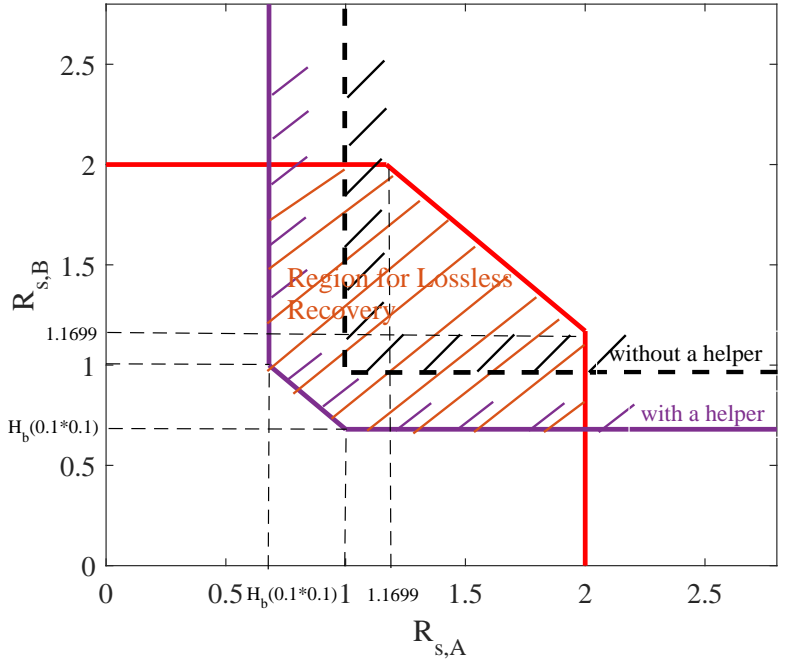

Figure 4. The region for lossless recovery for the MAC with a helper based on the sufficient condition.

$R_{c, \mathrm{~A}}=R_{c, \mathrm{~B}}=1 / 2, p_{e}=p_{d}=0.1$, and $\gamma_{\mathrm{A}, \mathrm{D}}=\gamma_{\mathrm{B}, \mathrm{D}}=0$ $\mathrm{dB}$. The region for lossless recovery is shown in Fig. 4, where we also include the Slepian-Wolf rate region without a helper as a reference. The region for lossless recovery is affected by various factors such as the values of $R_{c, \mathrm{~A}}, R_{c, \mathrm{~B}}$, $\gamma_{\mathrm{A}, \mathrm{D}}, \gamma_{\mathrm{B}, \mathrm{D}}, p_{e}$, and $p_{d}$. Increasing $\gamma_{\mathrm{A}, \mathrm{D}}$ and $\gamma_{\mathrm{B}, \mathrm{D}}$ results in expansion of the MAC capacity region while decreasing $p_{e}$ and $p_{d}$ results in expansion of the Slepian-Wolf rate region. In the next subsection on outage probability, we mainly focus on the factors $p_{e}$ and $p_{d}$, which are determined by the first MAC and the relay-to-destination link.

\section{Outage Probability}

For simplicity, we assume the same transmission rate is used for the two sources, i.e., $R_{c, \mathrm{~A}}=R_{c, \mathrm{~B}}=R_{c}$. Consequently, we define the event of successful transmission ${ }^{7}$ (i.e., lossless recovery of both the sources at the destination when the Slepian-Wolf rate region with a helper intersects with the MAC capacity region) as

$$
\begin{aligned}
& \mathcal{S}=\left\{H_{b}\left(p_{e} * p_{d}\right) \leq C\left(\gamma_{\mathrm{A}, \mathrm{D}}\right) / R_{c}\right. \\
& \wedge H_{b}\left(p_{e} * p_{d}\right) \leq C\left(\gamma_{\mathrm{B}, \mathrm{D}}\right) / R_{c} \wedge \\
& \left.1+H_{b}\left(p_{e} * p_{d}\right) \leq C\left(\gamma_{\mathrm{A}, \mathrm{D}}+\gamma_{\mathrm{B}, \mathrm{D}}\right) / R_{c}\right\},
\end{aligned}
$$

where $\wedge$ denotes logical "and". Therefore, the outage probability can be expressed as

$$
P_{\text {out }}=1-\operatorname{Pr}\{\mathcal{S}\} .
$$

Because the derived region for lossless recovery for the MAC with a helper might be smaller than that derived from the sufficient and necessary conditions, the outage probability is correspondingly a theoretical upper bound.

\footnotetext{
${ }^{7}$ The definition of successful transmission is the same as that in [16].
} 
Depending on the success or failure of source-to-relay $\mathrm{MAC}$ and relay-to-destination transmission, we can rewrite the $\operatorname{Pr}\{\mathcal{S}\}$ in $(25)$ as

$$
\operatorname{Pr}\{\mathcal{S}\}=\sum_{i=1}^{4} \operatorname{Pr}\left\{\mathcal{S} \mid \mathcal{C}_{i}\right\} \operatorname{Pr}\left\{\mathcal{C}_{i}\right\},
$$

where

$$
\begin{aligned}
& \mathcal{C}_{1}=\left\{p_{e}=0 \wedge p_{d}=0\right\}, \\
& \mathcal{C}_{2}=\left\{p_{e}=0 \wedge p_{d} \neq 0\right\}, \\
& \mathcal{C}_{3}=\left\{p_{e} \neq 0 \wedge p_{d}=0\right\}, \\
& \mathcal{C}_{4}=\left\{p_{e} \neq 0 \wedge p_{d} \neq 0\right\} .
\end{aligned}
$$

All the above four events will be transferred into different intervals of a three-dimensional vector consisting of $\gamma_{\mathrm{A}, \mathrm{R}}, \gamma_{\mathrm{B}, \mathrm{R}}$, $\gamma_{R, D}$. In addition to the effect of direct links from the sources to the destination, i.e., $\gamma_{\mathrm{A}, \mathrm{D}}$ and $\gamma_{\mathrm{B}, \mathrm{D}}$, the probability of successful transmission $\operatorname{Pr}\{\mathcal{S}\}$ can be calculated by five-fold integrals, i.e.,

$$
\begin{gathered}
\operatorname{Pr}\left\{\mathcal{S} \mid \mathcal{C}_{i}\right\} \operatorname{Pr}\left\{\mathcal{C}_{i}\right\}=\int \underset{\mathbb{V}_{i}}{\cdots} \int p\left(\gamma_{\mathrm{A}, \mathrm{R}}\right) p\left(\gamma_{\mathrm{B}, \mathrm{R}}\right) p\left(\gamma_{\mathrm{R}, \mathrm{D}}\right) p\left(\gamma_{\mathrm{A}, \mathrm{D}}\right) p\left(\gamma_{\mathrm{B}, \mathrm{D}}\right) \\
d \gamma_{\mathrm{A}, \mathrm{R}} d \gamma_{\mathrm{B}, \mathrm{R}} d \gamma_{\mathrm{R}, \mathrm{D}} d \gamma_{\mathrm{A}, \mathrm{D}} d \gamma_{\mathrm{B}, \mathrm{D}}, i \in\{1,2,3,4\}
\end{gathered}
$$

where $\mathbb{V}_{1}$ to $\mathbb{V}_{4}$ are defined in (29)-(32) with $\vee$ denotes logical "or". More details on (28) are provided in Appendix B.

\section{Practical Coding and Joint Decoding}

In this section, we describe a structure that implements a practical coding-decoding chain for transmission of both independent and correlated sources over the non-orthogonal MARC. Let us assume $0<\operatorname{Pr}(U=1)=p_{u} \leq 0.5$. The difference from the theoretical performance analyses is that we also include the case of transmitting correlated sources over the non-orthogonal MARC in the practical simulations. Notions used in this section are defined as follows.

- $L_{i}\left(x_{\mathrm{A}}^{k}\right)$ : initial channel LLR for $x_{\mathrm{A}}^{k}$;

- $L_{i}\left(x_{\mathrm{B}}^{k}\right)$ : initial channel LLR for $x_{\mathrm{B}}^{k}$;

- $L_{a}\left(x_{\mathrm{A}}^{k}\right):$ a priori LLR for $x_{\mathrm{A}}^{k}$ during the GI;

- $L_{a}\left(x_{\mathrm{B}}^{k}\right):$ a priori LLR for $x_{\mathrm{B}}^{k}$ during the GI;

- $L_{a}\left(u_{\mathrm{A}}^{k}\right)$ : a priori LLR for the $k$ th entry of $\mathbf{u}_{\mathrm{A}}$ (a sequence of realizations of $U_{\mathrm{A}}$ ), i.e., $u_{\mathrm{A}}^{k}$, during the GI;

- $L_{a}\left(u_{\mathrm{B}}^{k}\right):$ a priori $\mathrm{LLR}$ for the $k$ th entry of $\mathbf{u}_{\mathrm{B}}$ (a sequence of realizations of $U_{\mathrm{B}}$ ), i.e., $u_{\mathrm{B}}^{k}$, during the GI;

- $L_{a}\left(u_{\mathrm{R}}^{k}\right)$ : a priori LLR for the $k$ th entry of $\mathbf{u}_{\mathrm{R}}$ (a sequence of realizations of $\hat{U}_{\mathrm{A} \oplus \mathrm{B}}$ ), i.e., $u_{\mathrm{R}}^{k}$, during the GI;

- $L_{e}\left(x_{\mathrm{A}}^{k}\right)$ : extrinsic LLR for $x_{\mathrm{A}}^{k}$ during the GI;

- $L_{e}\left(x_{\mathrm{B}}^{k}\right)$ : extrinsic LLR for $x_{\mathrm{B}}^{k}$ during the GI;

- $L_{e}\left(u_{\mathrm{A}}^{k}\right)$ : extrinsic LLR for $u_{\mathrm{A}}^{k}$ during the GI;

- $L_{e}\left(u_{\mathrm{B}}^{k}\right)$ : extrinsic LLR for $u_{\mathrm{B}}^{k}$ during the GI;

- $L_{e}\left(u_{\mathrm{R}}^{k}\right)$ : extrinsic LLR for $u_{\mathrm{R}}^{k}$ during the GI;

- $L_{p}\left(u_{\mathrm{A}}^{k}\right)$ : a posteriori LLR for $u_{\mathrm{A}}^{k}$;

- $L_{p}\left(u_{\mathrm{B}}^{k}\right):$ a posteriori LLR for $u_{\mathrm{B}}^{k}$;

- $L_{p}\left(u_{\mathrm{R}}^{k}\right)$ : a posteriori LLR for $u_{\mathrm{R}}^{k}$;

- $K$ : the length of the binary information sequences;

- $\hat{p}_{u}$ : the estimate of correlation coefficient $p_{u}$;
- $\hat{p}_{e}$ : the estimate of the bit-flipping probability $p_{e}$;

- $y_{\mathrm{R}, 1}^{k}$ : the $k$ th entry of $\mathbf{y}_{\mathrm{R}, 1}$;

- $y_{\mathrm{D}, 1}^{k}$ : the $k$ th entry of $\mathbf{y}_{\mathrm{D}, 1}$.

\section{A. Channel Coding}

We use the identical structure ${ }^{8}$ of channel code for the sources and the relay, which is shown in Fig. 5. The structure is known as ACC aided turbo code, which has been widely applied in cooperative communication systems [6], [8], [10]. It consists of three components, i.e., rate- $R_{c}$ convolutional code $(\mathrm{CC})$, interleaver (e.g., $\Pi_{\mathrm{A}}$ ), and rate-1 ACC. The overall channel code rate is equal to $R_{c}$. The modulation scheme we consider here is binary phase shift keying (BPSK) with $0 \rightarrow 1$ and $1 \rightarrow-1$.

Compared to the more advanced LDPC codes, the ACC aided turbo codes can have a simpler structure and subsequently lower implementation complexity. Nevertheless, it has been demonstrated in [31] that the ACC aided turbo code with the generator polynomial of the non-recursive nonsystematic convolutional code (NSNRCC) being $G=([3,2])_{8}$ approaches the Shannon limit within $1.2 \mathrm{~dB}$ over AWGN channels at the BER level of $10^{-4}$. The performance loss, compared to the more advanced LDPC codes, is compensated for by the low computational complexity and power consumption. Hence, we consider the ACC aided turbo code with the generator polynomial of the NSNRCC being $G=([3,2])_{8}$ in the practical simulations due to its satisfactory performancecomplexity trade-off.

\section{B. MUD-XOR at Relay}

The block diagram of the MUD-XOR at relay is depicted in Fig. 6, where the ACC decoder is denoted by $\mathrm{ACC}^{-1}$, the deinterleavers are denoted by $\Pi_{\mathrm{A}}^{-1}$, and $\Pi_{\mathrm{B}}^{-1}$, the convonlutional decoder is denoted by $\mathrm{CC}^{-1}$, and the demapper is denoted by DMAP at the relay. Decoder input and output are marked with different colors for the purpose of better illustration. After receiving the signals from sources $\mathrm{A}$ and $\mathrm{B}$, the relay uses the demapping rule [32] to calculate the initial LLRs from the channels, which are the inputs for the two turbo decoders associated with the two sources. The detailed demapping rule is shown as follows:

$$
\begin{aligned}
& L_{i}\left(x_{\mathrm{A}}^{k}\right)=\ln \left(\frac{\sum_{i= \pm 1} \operatorname{Pr}\left(x_{\mathrm{A}}^{k}=1, x_{\mathrm{B}}^{k}=i \mid y_{\mathrm{R}, 1}^{k}\right)}{\sum_{i= \pm 1} \operatorname{Pr}\left(x_{\mathrm{A}}^{k}=-1, x_{\mathrm{B}}^{k}=i \mid y_{\mathrm{R}, 1}^{k}\right)}\right), \\
& L_{i}\left(x_{\mathrm{B}}^{k}\right)=\ln \left(\frac{\sum_{i= \pm 1} \operatorname{Pr}\left(x_{\mathrm{B}}^{k}=1, x_{\mathrm{A}}^{k}=i \mid y_{\mathrm{R}, 1}^{k}\right)}{\sum_{i= \pm 1} \operatorname{Pr}\left(x_{\mathrm{B}}^{k}=-1, x_{\mathrm{A}}^{k}=i \mid y_{\mathrm{R}, 1}^{k}\right)}\right) .
\end{aligned}
$$

Both local iteration (LI) and GI are involved in the MUDXOR process, as shown in Fig. 6. For the LI, i.e., iterations between the constituent decoders (convolutional decoder and ACC decoder), we use the Bahl-Cocke-Jelinek-Raviv (BCJR)

\footnotetext{
${ }^{8}$ The same structure does not necessarily mean the same code. Here, we use the same CC and ACC but different random interleavers.
} 


$$
\begin{aligned}
& \mathbb{V}_{1}=\underbrace{\left\{\gamma_{\mathrm{A}, \mathrm{R}} \geq \Phi^{-1}(1)\left(1+\gamma_{\mathrm{B}, \mathrm{R}}\right) \wedge \gamma_{\mathrm{B}, \mathrm{R}} \geq \Phi^{-1}(1)\right\} \vee\left\{\Phi^{-1}(1) \leq \gamma_{\mathrm{A}, \mathrm{R}} \leq \Phi^{-1}(1)\left(1+\gamma_{\mathrm{B}, \mathrm{R}}\right) \wedge \gamma_{\mathrm{A}, \mathrm{R}}+\gamma_{\mathrm{B}, \mathrm{R}} \geq 2^{R_{c, \mathrm{~A}}+R_{c, \mathrm{~B}}}-1\right\}}_{\left\{p_{e}=0\left(\mathcal{R}_{4}\right)\right\}} \\
& \wedge \underbrace{\left\{\gamma_{\mathrm{R}, \mathrm{D}} \geq \Phi^{-1}(1)\right\}}_{\left\{p_{d}=0\right\}} \wedge \underbrace{\left\{\gamma_{\mathrm{A}, \mathrm{D}} \geq \Phi^{-1}(0) \wedge \gamma_{\mathrm{B}, \mathrm{D}} \geq \Phi^{-1}(0) \wedge \gamma_{\mathrm{A}, \mathrm{D}}+\gamma_{\mathrm{B}, \mathrm{D}} \geq \Phi^{-1}(1)\right\}}_{\left\{\mathcal{S} \mid p_{e}=0, p_{d}=0\right\}}, \\
& \mathbb{V}_{2}=\underbrace{\left\{\gamma_{\mathrm{A}, \mathrm{R}} \geq \Phi^{-1}(1)\left(1+\gamma_{\mathrm{B}, \mathrm{R}}\right) \wedge \gamma_{\mathrm{B}, \mathrm{R}} \geq \Phi^{-1}(1)\right\} \vee\left\{\Phi^{-1}(1) \leq \gamma_{\mathrm{A}, \mathrm{R}} \leq \Phi^{-1}(1)\left(1+\gamma_{\mathrm{B}, \mathrm{R}}\right) \wedge \gamma_{\mathrm{A}, \mathrm{R}}+\gamma_{\mathrm{B}, \mathrm{R}} \geq 2^{R_{c, \mathrm{~A}}}+R_{c, \mathrm{~B}}-1\right\}}_{\left\{p_{e}=0\left(\mathcal{R}_{4}\right)\right\}} \\
& \wedge \underbrace{\left\{\Phi^{-1}(0) \leq \gamma_{\mathrm{R}, \mathrm{D}} \leq \Phi^{-1}(1)\right\}}_{\left\{p_{d} \neq 0\right\}} \wedge \underbrace{\left\{\gamma_{\mathrm{A}, \mathrm{D}} \geq \Phi^{-1}\left[H_{b}\left(p_{d}\right)\right] \wedge \gamma_{\mathrm{B}, \mathrm{D}} \geq \Phi^{-1}\left[H_{b}\left(p_{d}\right)\right] \wedge \gamma_{\mathrm{A}, \mathrm{D}}+\gamma_{\mathrm{B}, \mathrm{D}} \geq \Phi^{-1}\left[1+H_{b}\left(p_{d}\right)\right]\right.}_{\left\{\mathcal{S} \mid p_{e}=0, p_{d} \neq 0\right\}}, \\
& \mathbb{V}_{3}=\underbrace{\left\{\gamma_{\mathrm{A}, \mathrm{R}}<\Phi^{-1}(1) \wedge \gamma_{\mathrm{B}, \mathrm{R}}>\Phi^{-1}(1)\left(1+\gamma_{\mathrm{A}, \mathrm{R}}\right)\right\}}_{\left\{p_{e} \neq 0 \mid \mathcal{R}_{1}\right\}} \vee \underbrace{\left\{\gamma_{\mathrm{B}, \mathrm{R}}<\Phi^{-1}(1) \wedge \gamma_{\mathrm{A}, \mathrm{R}}>\Phi^{-1}(1)\left(1+\gamma_{\mathrm{B}, \mathrm{R}}\right)\right\}}_{\left\{p_{e} \neq 0 \mid \mathcal{R}_{2}\right\}} \\
& \wedge \underbrace{\left\{\gamma_{\mathrm{R}, \mathrm{D}} \geq \Phi^{-1}(1)\right\}}_{\left\{p_{d}=0\right\}} \wedge \underbrace{\left\{\gamma_{\mathrm{A}, \mathrm{D}} \geq \Phi^{-1}\left[H_{b}\left(p_{e}\right)\right] \wedge \gamma_{\mathrm{B}, \mathrm{D}} \geq \Phi^{-1}\left[H_{b}\left(p_{e}\right)\right] \wedge \gamma_{\mathrm{A}, \mathrm{D}}+\gamma_{\mathrm{B}, \mathrm{D}} \geq \Phi^{-1}\left[1+H_{b}\left(p_{e}\right)\right]\right\}}_{\left\{\mathcal{S} \mid p_{e} \neq 0, p_{d}=0\right\}}, \\
& \mathbb{V}_{4}=\underbrace{\left\{\gamma_{\mathrm{A}, \mathrm{R}}<\Phi^{-1}(1) \wedge \gamma_{\mathrm{B}, \mathrm{R}}>\Phi^{-1}(1)\left(1+\gamma_{\mathrm{A}, \mathrm{R}}\right)\right\}}_{\left\{p_{e} \neq 0 \mid \mathcal{R}_{1}\right\}} \vee \underbrace{\left\{\gamma_{\mathrm{B}, \mathrm{R}}<\Phi^{-1}(1) \wedge \gamma_{\mathrm{A}, \mathrm{R}}>\Phi^{-1}(1)\left(1+\gamma_{\mathrm{B}, \mathrm{R}}\right)\right\}}_{\left\{p_{e} \neq 0 \mid \mathcal{R}_{2}\right\}} \\
& \wedge \underbrace{\left\{\Phi^{-1}(0) \leq \gamma_{\mathrm{R}, \mathrm{D}} \leq \Phi^{-1}(1)\right\}}_{\left\{p_{d} \neq 0\right\}} \wedge \underbrace{\left\{\gamma_{\mathrm{A}, \mathrm{D}} \geq \Phi^{-1}\left[H_{b}\left(p_{e} * p_{d}\right)\right] \wedge \gamma_{\mathrm{B}, \mathrm{D}} \geq \Phi^{-1}\left[H_{b}\left(p_{e} * p_{d}\right)\right] \wedge \gamma_{\mathrm{A}, \mathrm{D}}+\gamma_{\mathrm{B}, \mathrm{D}} \geq \Phi^{-1}\left[1+H_{b}\left(p_{e} * p_{d}\right)\right]\right\}}_{\left\{\mathcal{S} \mid p_{e} \neq 0, p_{d} \neq 0\right\}} .
\end{aligned}
$$

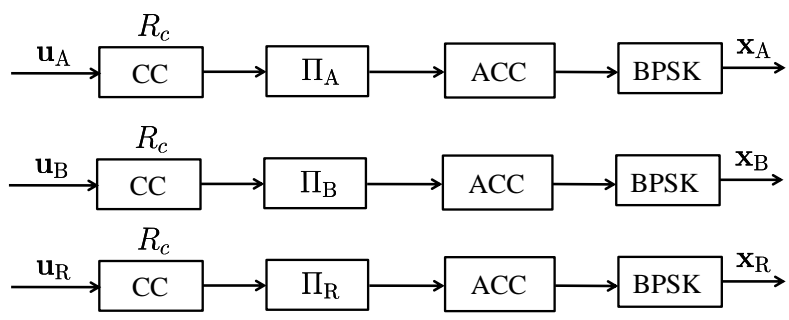

Figure 5. Channel coding and modulation structure at the two sources and the relay.

decoding algorithm [33]. During the $\mathrm{GI}^{9}$, the information exchange is expressed by (35)-(38).

1) Information Exchange between the $C C^{-1} s$ : The information exchange between the two convonlutional decoders follows the LLR updating rule in [34], characterized by the $f_{c}(\cdot, \cdot)$ function, which is defined in (35) and (36).

2) Information Exchange between the $A C C^{-1} s$ of Sources $A$ and $B$ : It should be noted that (37) and (38) follow the modified demapping rule, which takes the extrinsic information from the other ACC decoder into consideration. As shown in these formulations, (37) and (38) are functions of $y_{\mathrm{R}, 1}^{k}$, $P, G_{\mathrm{A}, \mathrm{R}}, G_{\mathrm{B}, \mathrm{R}} h_{\mathrm{A}, \mathrm{R}}, h_{\mathrm{B}, \mathrm{R}}$, and extrinsic LLRs from the ACC decoders. More details on (37) can be found in Appendix C.

In practice, the exact knowledge about $p_{u}$ is not available at the relay. However, it can be estimated and calculated during

\footnotetext{
${ }^{9}$ For the purpose of simplicity, we omit the iteration indexes in all the following equations.
}

each GI as [34],

$$
\hat{p}_{u}=\frac{1}{K} \sum_{k=1}^{K} \frac{\exp \left\{L_{p}\left(u_{\mathrm{A}}^{k}\right)\right\}+\exp \left\{L_{p}\left(u_{\mathrm{B}}^{k}\right)\right\}}{\left(1+\exp \left\{L_{p}\left(u_{\mathrm{A}}^{k}\right)\right\}\right)\left(1+\exp \left\{L_{p}\left(u_{\mathrm{A}}^{k}\right)\right\}\right)} .
$$

After reaching the stop criterion or achieving the maximum number of iterations, the relay performs bit-wise XOR on the estimates of sources $\mathrm{A}$ and $\mathrm{B}$ (i.e., $\hat{\mathbf{u}}_{\mathrm{A}}$ and $\hat{\mathbf{u}}_{\mathrm{B}}$ in Fig. 6), reencodes, modulates, and then transmits it to the destination regardless of whether errors are contained in the estimates or not.

\section{Joint Decoding at Destination}

The block diagram of the joint decoding is shown in Fig. 7, where global and local iterations are also needed during the decoding procedures. Similar to Fig. 6, decoder input and output are also marked with different colors. In this subsection, we reuse all the notations, which appear in the last subsection.

The GI also consists of two major parts, i.e., information exchange among the $\mathrm{CC}^{-1} \mathrm{~s}$ and information exchange between the $\mathrm{ACC}^{-1} \mathrm{~s}$ of sources $\mathrm{A}$ and $\mathrm{B}$.

1) Information Exchange among the $\mathrm{CC}^{-1} \mathrm{~s}$ : Different from the boxplus operations in [6], the information exchange here takes into consideration of the probability of the intralink errors. The a priori LLR information of source A, output of the modified boxplus operation in Fig. 7, can be expressed as

$$
L_{a}\left(u_{\mathrm{A}}^{k}\right)=\ln \left(\frac{\operatorname{Pr}\left(\oplus\left\{u_{\mathrm{B}}^{k}, u_{\mathrm{R}}^{k}, e^{k}\right\}=0\right)}{\operatorname{Pr}\left(\oplus\left\{u_{\mathrm{B}}^{k}, u_{\mathrm{R}}^{k}, e^{k}\right\}=1\right)}\right),
$$

where $\oplus$ is implemented in the bit-wise mode, and $e^{k}$ is the $k$ th entry of $\mathbf{e}$ (a sequence of realizations of $E$ ). Similarly, the 


$$
\begin{gathered}
L_{a}\left(u_{\mathrm{A}}^{k}\right)=f_{c}\left(L_{e}\left(u_{\mathrm{B}}^{k}\right), \hat{p}_{u}\right)=\ln \left(\frac{\left(1-\hat{p}_{u}\right) \exp \left\{L_{e}\left(u_{\mathrm{B}}^{k}\right)\right\}+\hat{p}_{u}}{\left(1-\hat{p}_{u}\right)+\hat{p}_{u} \exp \left\{L_{e}\left(u_{\mathrm{B}}^{k}\right)\right\}}\right), \\
L_{a}\left(u_{\mathrm{B}}^{k}\right)=f_{c}\left(L_{e}\left(u_{\mathrm{A}}^{k}\right), \hat{p}_{u}\right)=\ln \left(\frac{\left(1-\hat{p}_{u}\right) \exp \left\{L_{e}\left(u_{\mathrm{A}}^{k}\right)\right\}+\hat{p}_{u}}{\left(1-\hat{p}_{u}\right)+\hat{p}_{u} \exp \left\{L_{e}\left(u_{\mathrm{A}}^{k}\right)\right\}}\right) . \\
L_{a}\left(x_{\mathrm{A}}^{k}\right)=\ln \left(\frac{\exp \left(L_{e}\left(x_{\mathrm{B}}^{k}\right)-\left|y_{\mathrm{R}, 1}^{k}-\sqrt{P G_{\mathrm{A}, \mathrm{R}}} h_{\mathrm{A}, \mathrm{R}}-\sqrt{P G_{\mathrm{B}, \mathrm{R}}} h_{\mathrm{B}, \mathrm{R}}\right|^{2}\right)+\exp \left(-\left|y_{\mathrm{R}, 1}^{k}-\sqrt{P G_{\mathrm{A}, \mathrm{R}}} h_{\mathrm{A}, \mathrm{R}}+\sqrt{P G_{\mathrm{B}, \mathrm{R}}} h_{\mathrm{B}, \mathrm{R}}\right|^{2}\right)}{\exp \left(-\left|y_{\mathrm{R}, 1}^{k}+\sqrt{P G_{\mathrm{A}, \mathrm{R}}} h_{\mathrm{A}, \mathrm{R}}+\sqrt{P G_{\mathrm{B}, \mathrm{R}}} h_{\mathrm{B}, \mathrm{R}}\right|^{2}\right)+\exp \left(L_{e}\left(x_{\mathrm{B}}^{k}\right)-\left|y_{\mathrm{R}, 1}^{k}+\sqrt{P G_{\mathrm{A}, \mathrm{R}}} h_{\mathrm{A}, \mathrm{R}}-\sqrt{P G_{\mathrm{B}, \mathrm{R}}} h_{\mathrm{B}, \mathrm{R}}\right|^{2}\right)}\right), \\
L_{a}\left(x_{\mathrm{B}}^{k}\right)=\ln \left(\frac{\exp \left(L_{e}\left(x_{\mathrm{A}}^{k}\right)-\left|y_{\mathrm{R}, 1}^{k}-\sqrt{P G_{\mathrm{A}, \mathrm{R}}} h_{\mathrm{A}, \mathrm{R}}-\sqrt{P G_{\mathrm{B}, \mathrm{R}}} h_{\mathrm{B}, \mathrm{R}}\right|^{2}\right)+\exp \left(-\left|y_{\mathrm{R}, 1}^{k}+\sqrt{P G_{\mathrm{A}, \mathrm{R}}} h_{\mathrm{A}, \mathrm{R}}-\sqrt{P G_{\mathrm{B}, \mathrm{R}}} h_{\mathrm{B}, \mathrm{R}}\right|^{2}\right)}{\exp \left(-\left|y_{\mathrm{R}, 1}^{k}+\sqrt{P G_{\mathrm{A}, \mathrm{R}}} h_{\mathrm{A}, \mathrm{R}}+\sqrt{P G_{\mathrm{B}, \mathrm{R}}} h_{\mathrm{B}, \mathrm{R}}\right|^{2}\right)+\exp \left(L_{e}\left(x_{\mathrm{A}}^{k}\right)-\left|y_{\mathrm{R}, 1}^{k}-\sqrt{P G_{\mathrm{A}, \mathrm{R}}} h_{\mathrm{A}, \mathrm{R}}+\sqrt{P G_{\mathrm{B}, \mathrm{R}}} h_{\mathrm{B}, \mathrm{R}}\right|^{2}\right)}\right),
\end{gathered}
$$

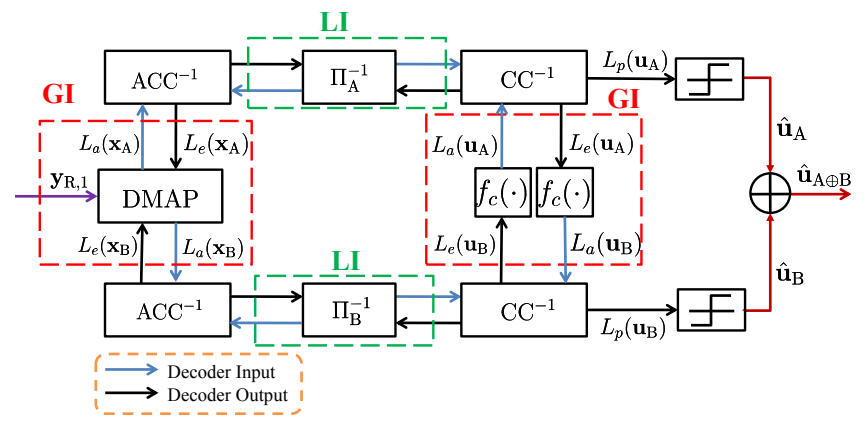

Figure 6. Block diagram of MUD-XOR at the relay.

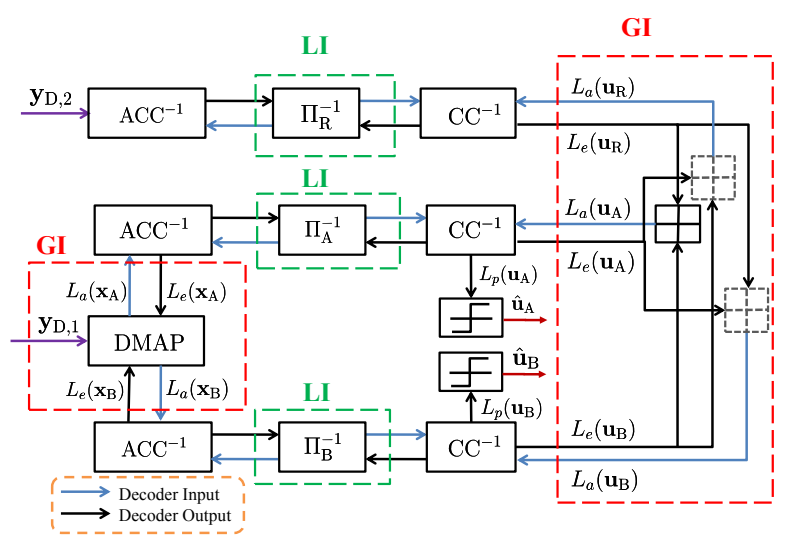

Figure 7. Block diagram of joint decoding at the destination.

a priori LLR information of source B and the relay can be expressed as

$$
\begin{aligned}
& L_{a}\left(u_{\mathrm{B}}^{k}\right)=\ln \left(\frac{\operatorname{Pr}\left(\oplus\left\{u_{\mathrm{A}}^{k}, u_{\mathrm{R}}^{k}, e^{k}\right\}=0\right)}{\operatorname{Pr}\left(\oplus\left\{u_{\mathrm{A}}^{k}, u_{\mathrm{R}}^{k}, e^{k}\right\}=1\right)}\right), \\
& L_{a}\left(u_{\mathrm{R}}^{k}\right)=\ln \left(\frac{\operatorname{Pr}\left(\oplus\left\{u_{\mathrm{A}}^{k}, u_{\mathrm{B}}^{k}, e^{k}\right\}=0\right)}{\operatorname{Pr}\left(\oplus\left\{u_{\mathrm{A}}^{k}, u_{\mathrm{B}}^{k}, e^{k}\right\}=1\right)}\right) .
\end{aligned}
$$

There exist $2^{3}=8$ combinations for $\left\{u_{\mathrm{B}}^{k}, u_{\mathrm{R}}^{k}, e^{k}\right\}$ in (40), i.e., $\left\{u_{\mathrm{B}}^{k}=0, u_{\mathrm{R}}^{k}=0, e^{k}=0\right\},\left\{u_{\mathrm{B}}^{k}=0, u_{\mathrm{R}}^{k}=0, e^{k}=1\right\}$, $\left\{u_{\mathrm{B}}^{k}=0, u_{\mathrm{R}}^{k}=1, e^{k}=0\right\},\left\{u_{\mathrm{B}}^{k}=0, u_{\mathrm{R}}^{k}=1, e^{k}=1\right\}$, $\left\{u_{\mathrm{B}}^{k}=1, u_{\mathrm{R}}^{k}=0, e^{k}=0\right\},\left\{u_{\mathrm{B}}^{k}=1, u_{\mathrm{R}}^{k}=0, e^{k}=1\right\}$, $\left\{u_{\mathrm{B}}^{k}=1, u_{\mathrm{R}}^{k}=1, e^{k}=0\right\}$, and $\left\{u_{\mathrm{B}}^{k}=1, u_{\mathrm{R}}^{k}=1, e^{k}=\right.$
$1\}$. Four of the combinations are included in the numerator of (40) while the remaining are included in the denominator of (40). After some manipulations, (40)-(42) can be further expressed in (43)-(45). We offer detailed information on (43) in Appendix C. Similarly, (44) and (45) can be derived in the same manner as (43).

Similarly to (39), the bit-flipping probability $p_{e}$ at the first MAC can be estimated at the destination by (46). More details on (46) are also provided in Appendix C.

2) Information Exchange between the $A C C^{-1} s$ of Sources $A$ and B: Similar to (37) and (38) in the MUD-XOR process, the information updating rule for $L_{a}\left(x_{\mathrm{A}}^{k}\right)$ and $L_{a}\left(x_{\mathrm{B}}^{k}\right)$ is expressed in (47) and (48). As shown in these formulations, (47) and (48) are functions of $\mathbf{y}_{\mathrm{D}, 1}^{k}, P, G_{\mathrm{A}, \mathrm{D}}, G_{\mathrm{B}, \mathrm{D}} h_{\mathrm{A}, \mathrm{D}}, h_{\mathrm{B}, \mathrm{D}}$, and extrinsic LLRs from the ACC decoders.

\section{Simulation Results}

In this section, we draw the theoretical and practical simulation results in terms of the outage probability and FER over the non-orthogonal MARC. All the transmission rates are set to be 0.5 . The correlation coefficient between the sources ranges from 0 to 0.5 . In the practical coding-decoding chain, we set $K=1000$ (i.e., $N=2000$ ) and use random interleavers [35]. The GI is performed after every LI, and the maximum number of GI is set to 15. Orthogonal transmission with imperfect intra links from [8] is considered as a benchmark scheme. Four different scenarios are taken into consideration.

1) Scenario One (Equal Distance for All the Links): In this scenario, we assume $d_{\mathrm{R}, \mathrm{D}}=d_{\mathrm{A}, \mathrm{R}}=d_{\mathrm{B}, \mathrm{R}}=d_{\mathrm{A}, \mathrm{D}}=d_{\mathrm{B}, \mathrm{D}}$ with $d_{\mathrm{R}, \mathrm{D}}, d_{\mathrm{A}, \mathrm{R}}, d_{\mathrm{B}, \mathrm{R}}, d_{\mathrm{A}, \mathrm{D}}, d_{\mathrm{B}, \mathrm{D}}$ denoting the distances of relay-todestination, source A-to-relay, source B-to-relay, source A-todestination, and source B-to-destination, respectively. In other words, the geometric gains have the following relationship: $G_{\mathrm{R}, \mathrm{D}}=G_{\mathrm{A}, \mathrm{R}}=G_{\mathrm{B}, \mathrm{R}}=G_{\mathrm{A}, \mathrm{D}}=G_{\mathrm{B}, \mathrm{D}}$, by ignoring shadowing variations.

2) Scenario Two (Relay in the Middle): In this scenario ${ }^{10}$, we assume $d_{\mathrm{R}, \mathrm{D}}=d_{\mathrm{A}, \mathrm{R}}=d_{\mathrm{B}, \mathrm{R}}=0.6 \times d_{\mathrm{A}, \mathrm{D}}=0.6 \times d_{\mathrm{B}, \mathrm{D}}$. In other words, the geometric gains have the following relationship: $G_{\mathrm{R}, \mathrm{D}}=G_{\mathrm{A}, \mathrm{R}}=G_{\mathrm{B}, \mathrm{R}}=G_{\mathrm{A}, \mathrm{D}}+7.81 \mathrm{~dB}=$ $G_{\mathrm{B}, \mathrm{D}}+7.81 \mathrm{~dB}$ under the condition that the path-loss exponent is set to 3.52 [36].

\footnotetext{
${ }^{10}$ In the middle means the relay has the same distance to the two sources and the destination.
} 


$$
\begin{gathered}
L_{a}\left(u_{\mathrm{A}}^{k}\right)=\ln \left(\frac{\left(1-\hat{p}_{e}\right)\left(1-\hat{p}_{u}\right) \exp \left\{L_{e}\left(u_{\mathrm{B}}^{k}\right)+L_{e}\left(u_{\mathrm{R}}^{k}\right)\right\}+\left(1-\hat{p}_{e}\right) \hat{p}_{u}+\hat{p}_{e}\left(1-\hat{p}_{u}\right) \exp \left\{L_{e}\left(u_{\mathrm{B}}^{k}\right)\right\}+\hat{p}_{e} \hat{p}_{u} \exp \left\{L_{e}\left(u_{\mathrm{R}}^{k}\right)\right\}}{\left(1-\hat{p}_{e}\right) \hat{p}_{u} \exp \left\{L_{e}\left(u_{\mathrm{B}}^{k}\right)\right\}+\left(1-\hat{p}_{e}\right)\left(1-\hat{p}_{u}\right) \exp \left\{L_{e}\left(u_{\mathrm{R}}^{k}\right)\right\}+\hat{p}_{e} \hat{p}_{u} \exp \left\{L_{e}\left(u_{\mathrm{B}}^{k}\right)+L_{e}\left(u_{\mathrm{R}}^{k}\right)\right\}+\hat{p}_{e}\left(1-\hat{p}_{u}\right)}\right) \\
L_{a}\left(u_{\mathrm{B}}^{k}\right)=\ln \left(\frac{\left(1-\hat{p}_{e}\right)\left(1-\hat{p}_{u}\right) \exp \left\{L_{e}\left(u_{\mathrm{A}}^{k}\right)+L_{e}\left(u_{\mathrm{R}}^{k}\right)\right\}+\left(1-\hat{p}_{e}\right) \hat{p}_{u}+\hat{p}_{e}\left(1-\hat{p}_{u}\right) \exp \left\{L_{e}\left(u_{\mathrm{A}}^{k}\right)\right\}+\hat{p}_{e} \hat{p}_{u} \exp \left\{L_{e}\left(u_{\mathrm{R}}^{k}\right)\right\}}{\left(1-\hat{p}_{e}\right) \hat{p}_{u} \exp \left\{L_{e}\left(u_{\mathrm{A}}^{k}\right)\right\}+\left(1-\hat{p}_{e}\right)\left(1-\hat{p}_{u}\right) \exp \left\{L_{e}\left(u_{\mathrm{R}}^{k}\right)\right\}+\hat{p}_{e} \hat{p}_{u} \exp \left\{L_{e}\left(u_{\mathrm{A}}^{k}\right)+L_{e}\left(u_{\mathrm{R}}^{k}\right)\right\}+\hat{p}_{e}\left(1-\hat{p}_{u}\right)}\right) \\
(44) \\
L_{a}\left(u_{\mathrm{R}}^{k}\right)=\ln \left(\frac{\left(1-\hat{p}_{e}\right)\left(1-\hat{p}_{u}\right)\left(1+\exp \left\{L_{e}\left(u_{\mathrm{A}}^{k}\right)+L_{e}\left(u_{\mathrm{B}}^{k}\right)\right\}\right)+\hat{p}_{e} \hat{p}_{u}\left(\exp \left\{L_{e}\left(u_{\mathrm{A}}^{k}\right)\right\}+\exp \left\{L_{e}\left(u_{\mathrm{B}}^{k}\right)\right\}\right)}{\left(1-\hat{p}_{e}\right) \hat{p}_{u}\left(\exp \left\{L_{e}\left(u_{\mathrm{A}}^{k}\right)\right\}+\exp \left\{L_{e}\left(u_{\mathrm{B}}^{k}\right)\right\}\right)+\hat{p}_{e}\left(1-\hat{p}_{u}\right)\left(1+\exp \left\{L_{e}\left(u_{\mathrm{A}}^{k}\right)+L_{e}\left(u_{\mathrm{B}}^{k}\right)\right\}\right)}\right) . \\
(45) \\
\hat{p}_{e}=\frac{1}{K} \sum_{k=1}^{K} \frac{\exp \left\{L_{p}\left(u_{\mathrm{A}}^{k}\right)+L_{p}\left(u_{\mathrm{B}}^{k}\right)\right\}+\exp \left\{L_{p}\left(u_{\mathrm{A}}^{k}\right)+L_{p}\left(u_{\mathrm{R}}^{k}\right)\right\}+\exp \left\{L_{p}\left(u_{\mathrm{B}}^{k}\right)+L_{p}\left(u_{\mathrm{R}}^{k}\right)\right\}+1}{\left(1+\exp \left\{L_{p}\left(u_{\mathrm{A}}^{k}\right)\right\}\right)\left(1+\exp \left\{L_{p}\left(u_{\mathrm{B}}^{k}\right)\right\}\right)\left(1+\exp \left\{L_{p}\left(u_{\mathrm{R}}^{k}\right)\right\}\right)} .
\end{gathered}
$$

$L_{a}\left(x_{\mathrm{A}}^{k}\right)=\ln \left(\frac{\exp \left(L_{e}\left(x_{\mathrm{B}}^{k}\right)\right) \exp \left(-\left|y_{\mathrm{D}, 1}^{k}-\sqrt{P G_{\mathrm{A}, \mathrm{D}}} h_{\mathrm{A}, \mathrm{D}}-\sqrt{P G_{\mathrm{B}, \mathrm{D}}} h_{\mathrm{B}, \mathrm{D}}\right|^{2}\right)+\exp \left(-\left|y_{\mathrm{D}, 1}^{k}-\sqrt{P G_{\mathrm{A}, \mathrm{D}}} h_{\mathrm{A}, \mathrm{D}}+\sqrt{P G_{\mathrm{B}, \mathrm{D}}} h_{\mathrm{B}, \mathrm{D}}\right|^{2}\right)}{\exp \left(-\left|y_{\mathrm{D}, 1}^{k}+\sqrt{P G_{\mathrm{A}, \mathrm{D}}} h_{\mathrm{A}, \mathrm{D}}+\sqrt{P G_{\mathrm{B}, \mathrm{D}}} h_{\mathrm{B}, \mathrm{D}}\right|^{2}\right)+\exp \left(L_{e}\left(x_{\mathrm{B}}^{k}\right)\right) \exp \left(-\left|y_{\mathrm{D}, 1}^{k}+\sqrt{P G_{\mathrm{A}, \mathrm{D}}} h_{\mathrm{A}, \mathrm{D}}-\sqrt{P G_{\mathrm{B}, \mathrm{D}}} h_{\mathrm{B}, \mathrm{D}}\right|^{2}\right)}\right)$

$L_{a}\left(x_{\mathrm{B}}^{k}\right)=\ln \left(\frac{\exp \left(L_{e}\left(x_{\mathrm{A}}^{k}\right)\right) \exp \left(-\left|y_{\mathrm{D}, 1}^{k}-\sqrt{P G_{\mathrm{A}, \mathrm{D}}} h_{\mathrm{A}, \mathrm{D}}-\sqrt{P G_{\mathrm{B}, \mathrm{D}}} h_{\mathrm{B}, \mathrm{D}}\right|^{2}\right)+\exp \left(-\left|y_{\mathrm{D}, 1}^{k}+\sqrt{P G_{\mathrm{A}, \mathrm{D}}} h_{\mathrm{A}, \mathrm{D}}-\sqrt{P G_{\mathrm{B}, \mathrm{D}}} h_{\mathrm{B}, \mathrm{D}}\right|^{2}\right)}{\exp \left(-\left|y_{\mathrm{D}, 1}^{k}+\sqrt{P G_{\mathrm{A}, \mathrm{D}}} h_{\mathrm{A}, \mathrm{D}}+\sqrt{P G_{\mathrm{B}, \mathrm{D}}} h_{\mathrm{B}, \mathrm{D}}\right|^{2}\right)+\exp \left(L_{e}\left(x_{\mathrm{A}}^{k}\right)\right) \exp \left(-\left|y_{\mathrm{D}, 1}^{k}-\sqrt{P G_{\mathrm{A}, \mathrm{D}}} h_{\mathrm{A}, \mathrm{D}}+\sqrt{P G_{\mathrm{B}, \mathrm{D}}} h_{\mathrm{B}, \mathrm{D}}\right|^{2}\right)}\right)$.

3) Scenario Three (Relay Closer to the Sources): In this scenario, we assume $d_{\mathrm{A}, \mathrm{R}}=d_{\mathrm{B}, \mathrm{R}}=0.4 \times d_{\mathrm{A}, \mathrm{D}}=0.4 \times d_{\mathrm{B}, \mathrm{D}}$ and $d_{\mathrm{R}, \mathrm{D}}=0.8 \times d_{\mathrm{A}, \mathrm{D}}=0.8 \times d_{\mathrm{B}, \mathrm{D}}$. In other words, the geometric gains have the following relationship: $G_{\mathrm{A}, \mathrm{R}}=G_{\mathrm{B}, \mathrm{R}}=G_{\mathrm{A}, \mathrm{D}}+$ $14.01 \mathrm{~dB}=G_{\mathrm{B}, \mathrm{D}}+14.01 \mathrm{~dB}$ and $G_{\mathrm{R}, \mathrm{D}}=G_{\mathrm{A}, \mathrm{D}}+3.40 \mathrm{~dB}=$ $G_{\mathrm{B}, \mathrm{D}}+3.40 \mathrm{~dB}$.

4) Scenario Four (Relay Closer to the Destination): In this scenario, we assume $d_{\mathrm{A}, \mathrm{R}}=d_{\mathrm{B}, \mathrm{R}}=0.8 \times d_{\mathrm{A}, \mathrm{D}}=0.8 \times d_{\mathrm{B}, \mathrm{D}}$ and $d_{\mathrm{R}, \mathrm{D}}=0.4 \times d_{\mathrm{A}, \mathrm{D}}=0.4 \times d_{\mathrm{B}, \mathrm{D}}$. In other words, the geometric gains have the following relationship: $G_{\mathrm{A}, \mathrm{R}}=G_{\mathrm{B}, \mathrm{R}}=G_{\mathrm{A}, \mathrm{D}}+$ $3.40 \mathrm{~dB}=G_{\mathrm{B}, \mathrm{D}}+3.40 \mathrm{~dB}$ and $G_{\mathrm{R}, \mathrm{D}}=G_{\mathrm{A}, \mathrm{D}}+14.01 \mathrm{~dB}=$ $G_{\mathrm{B}, \mathrm{D}}+14.01 \mathrm{~dB}$.

\section{A. Independent Sources}

The simulation results for the case of independent sources are provided in Fig. 8, where "FER" represents the FER curves obtained by using the practical coding-decoding chain described in Section IV, "Theo" represents the theoretical results of the outage probability for the non-orthogonal MARC given by (25), and "Theo [8]" represents the theoretical results of the outage probability for the orthogonal MARC from [8] with imperfect intra links. Compared to the case in [8], the performance loss is very limited for the non-orthogonal MARC also with imperfect intra links. Second order diversity can be achieved for all the scenarios. The gap between theoretical outage probability and FER obtained by using ACC aided turbo code is within $4 \mathrm{~dB}$ for all the scenarios at the FER level of $10^{-3}$. It is not difficult to observe that scenario one is the worst among all the four scenarios while scenario two and scenario three are the best and have almost the same

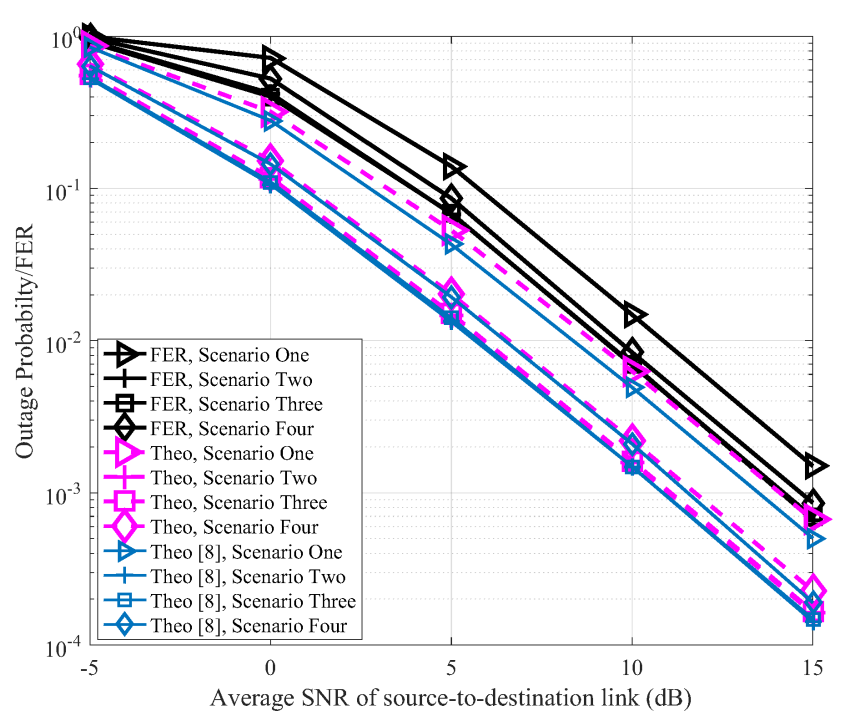

Figure 8. Outage probabilities and FERs of transmitting independent sources over the non-orthogonal MARC.

performance in terms of both FER and theoretical outage probability. In this sense, the best relay position should be closer to the sources or in the middle between the sources and destination.

The throughput of the non-orthogonal MARC is shown in Fig. 9, where the overall time slots are taken into consideration. The results from [8] are also offered as benchmark schemes. From the simulation curves, we could easily observe 


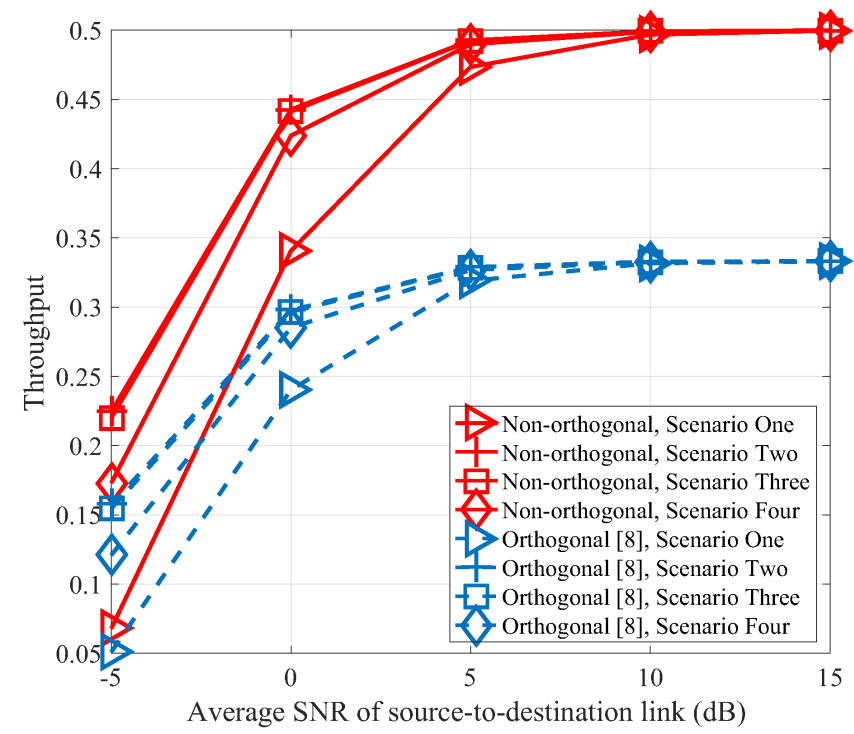

Figure 9. Throughput of transmitting independent sources over the nonorthogonal MARC.

that non-orthogonal transmission significantly outperforms its orthogonal counterpart. At the high SNR regime, the throughput of the non-orthogonal MARC is roughly 1.5 times of that of the orthogonal MARC.

\section{B. Correlated Sources}

In the theoretical outage analyses for the case of correlated sources, obtaining distortion for the first MAC is an open problem [27]. Hence, we evaluate the performance of such case by simulations only. We perform the simulations via a practical coding-decoding structure as the one used in the case of independent sources. This could offer performance tendency intuitively of transmitting correlated sources over the non-orthogonal MARC. The simulation results are shown in Fig. 10. We omit the curve for scenario three, since it is almost the same as that for scenario two ${ }^{11}$. The performance improves as the correlation between the two sources increases. It should be noticed that second order diversity can be achieved for all the scenarios. When $p_{u}$ approaches zero, all the scenarios have almost the same outage performance, since the relay becomes helpless and the transmission only relies on the direct links.

\section{CONClusions AND Future Work}

We have calculated the outage probability for the transmission of independent sources over the non-orthogonal fading MARC, which is based on the sufficient condition of lossless communication over MAC with the aid of a helper. Since we use sufficient condition only, the derived outage is a theoretical upper bound. Thus, the outage derivation provides a safer side network design reference. It has been found that the throughput of the non-orthogonal MARC can be significantly improved compared to its orthogonal counterpart.

\footnotetext{
${ }^{11}$ Performance similarity between the curves for scenario two and scenario three is also observed in Fig. 8.
}

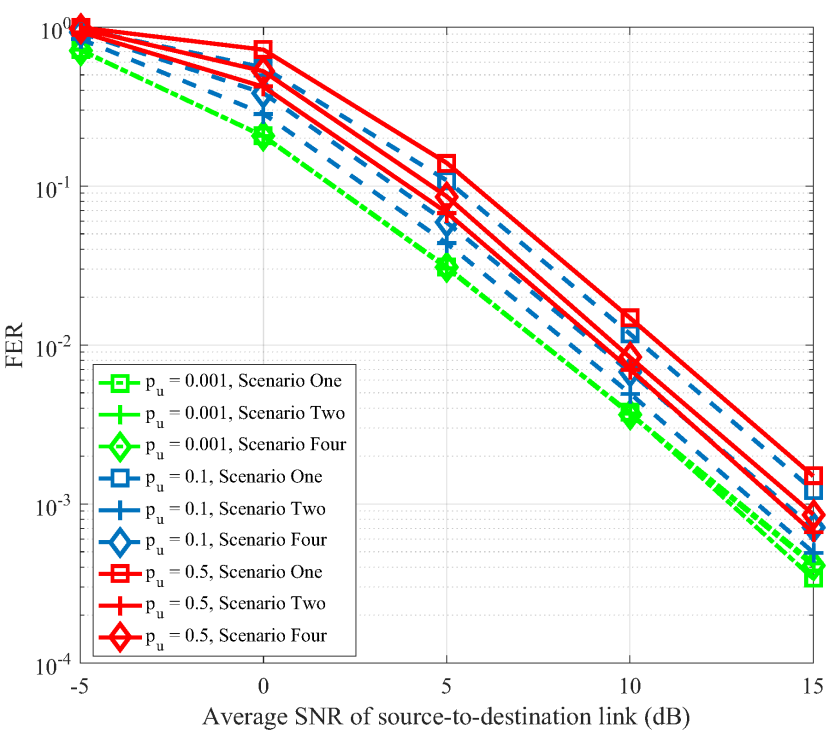

Figure 10. FERs of transmitting correlated sources over the non-orthogonal MARC.

A computationally-/energy-efficient scheme with ACCaided turbo code has been then proposed, where the FER performance has been shown to closely approach the theoretical upper bound of the outage probability.

Time and power allocation are potential tools for the improvement of the outage performance, which will be considered as our future work. The theoretical outage analysis we have provided is only for the case of independent sources, and the correlated case is left as future study. The necessary and sufficient conditions for the MAC with a helper are also a potential problem for future investigation.

The sources keep silent during the second time slot in the paper. A natural extension would be that additional parity bits are transmitted from the sources during the second time slot. Therefore, a comprehensive study is needed to identify its potential benefits over the transmission scheme studied in the paper. The optimization of encoding-decoding chain and the selection of better codes are also left for future investigation.

\section{APPENDIX A \\ DERIVATION OF (16) - (18)}

According to the chain rule for entropy, the joint entropy of $U_{\mathrm{A}}, U_{\mathrm{B}}, \hat{U}_{\mathrm{A} \oplus \mathrm{B}}$, and $\tilde{U}_{\mathrm{A} \oplus \mathrm{B}}$ can be written by

$$
\begin{aligned}
& H\left(U_{\mathrm{A}}, U_{\mathrm{B}}, \hat{U}_{\mathrm{A} \oplus \mathrm{B}}, \tilde{U}_{\mathrm{A} \oplus \mathrm{B}}\right)=H\left(U_{\mathrm{A}}\right)+H\left(U_{\mathrm{B}} \mid U_{\mathrm{A}}\right) \\
& +H\left(\hat{U}_{\mathrm{A} \oplus \mathrm{B}} \mid U_{\mathrm{A}}, U_{\mathrm{B}}\right)+H\left(\tilde{U}_{\mathrm{A} \oplus \mathrm{B}} \mid U_{\mathrm{A}}, U_{\mathrm{B}}, \hat{U}_{\mathrm{A} \oplus \mathrm{B}}\right),
\end{aligned}
$$

where $H\left(U_{\mathrm{A}}\right)=1, H\left(U_{\mathrm{B}} \mid U_{\mathrm{A}}\right)=1, H\left(\hat{U}_{\mathrm{A} \oplus \mathrm{B}} \mid U_{\mathrm{A}}, U_{\mathrm{B}}\right)=$ $H_{b}\left(p_{e}\right)$, and $H\left(\tilde{U}_{\mathrm{A} \oplus \mathrm{B}} \mid U_{\mathrm{A}}, U_{\mathrm{B}}, \hat{U}_{\mathrm{A} \oplus \mathrm{B}}\right)=H_{b}\left(p_{d}\right)$.

Moreover, we can also express $H\left(U_{\mathrm{A}}, U_{\mathrm{B}}, \hat{U}_{\mathrm{A} \oplus \mathrm{B}}, \tilde{U}_{\mathrm{A} \oplus \mathrm{B}}\right)$ in the form of

$$
\begin{aligned}
& H\left(U_{\mathrm{A}}, U_{\mathrm{B}}, \hat{U}_{\mathrm{A} \oplus \mathrm{B}}, \tilde{U}_{\mathrm{A} \oplus \mathrm{B}}\right)=H\left(\tilde{U}_{\mathrm{A} \oplus \mathrm{B}}\right)+H\left(U_{\mathrm{A}}, U_{\mathrm{B}} \mid \tilde{U}_{\mathrm{A} \oplus \mathrm{B}}\right) \\
& +H\left(\hat{U}_{\mathrm{A} \oplus \mathrm{B}} \mid U_{\mathrm{A}}, U_{\mathrm{B}}, \tilde{U}_{\mathrm{A} \oplus \mathrm{B}}\right),
\end{aligned}
$$

where $H\left(\tilde{U}_{\mathrm{A} \oplus \mathrm{B}}\right)=1$. 
We have the following expression for the conditional mutual information,

$$
\begin{aligned}
& I\left(\hat{U}_{\mathrm{A} \oplus \mathrm{B}} ; \tilde{U}_{\mathrm{A} \oplus \mathrm{B}} \mid U_{\mathrm{A}}, U_{\mathrm{B}}\right)=H\left(\hat{U}_{\mathrm{A} \oplus \mathrm{B}} \mid U_{\mathrm{A}}, U_{\mathrm{B}}\right) \\
& -H\left(\hat{U}_{\mathrm{A} \oplus \mathrm{B}} \mid U_{\mathrm{A}}, U_{\mathrm{B}}, \tilde{U}_{\mathrm{A} \oplus \mathrm{B}}\right) \\
& =H\left(\tilde{U}_{\mathrm{A} \oplus \mathrm{B}} \mid U_{\mathrm{A}}, U_{\mathrm{B}}\right)-H\left(\tilde{U}_{\mathrm{A} \oplus \mathrm{B}} \mid U_{\mathrm{A}}, U_{\mathrm{B}}, \hat{U}_{\mathrm{A} \oplus \mathrm{B}}\right) .
\end{aligned}
$$

According to (51), we can get

$$
H\left(\hat{U}_{\mathrm{A} \oplus \mathrm{B}} \mid U_{\mathrm{A}}, U_{\mathrm{B}}, \tilde{U}_{\mathrm{A} \oplus \mathrm{B}}\right)=H_{b}\left(p_{e}\right)+H_{b}\left(p_{d}\right)-H_{b}\left(p_{e} * p_{d}\right) .
$$

By combining (49), (50), and (52), we can obtain

$$
H\left(U_{\mathrm{A}}, U_{\mathrm{B}} \mid \tilde{U}_{\mathrm{A} \oplus \mathrm{B}}\right)=1+H_{b}\left(p_{e} * p_{d}\right) .
$$

For the term $H\left(U_{\mathrm{A}} \mid U_{\mathbf{B}}, \tilde{U}_{\mathbf{A} \oplus \mathbf{B}}\right)$ in (16), we can refer to the following derivation

$$
H\left(U_{\mathrm{A}} \mid U_{\mathrm{B}}, \tilde{U}_{\mathrm{A} \oplus \mathrm{B}}\right)=H\left(U_{\mathrm{A}}, U_{\mathrm{B}} \mid \tilde{U}_{\mathrm{A} \oplus \mathrm{B}}\right)-H\left(U_{\mathrm{B}} \mid \tilde{U}_{\mathrm{A} \oplus \mathrm{B}}\right),
$$

where $H\left(U_{\mathrm{B}} \mid \tilde{U}_{\mathrm{A} \oplus \mathrm{B}}\right)=1$. Then, we get

$$
H\left(U_{\mathrm{A}} \mid U_{\mathrm{B}}, \tilde{U}_{\mathrm{A} \oplus \mathrm{B}}\right)=H_{b}\left(p_{e} * p_{d}\right) .
$$

Due to the symmetry property of $U_{\mathrm{A}}$ and $U_{\mathrm{B}}$, it is easy to get

$$
H\left(U_{\mathrm{B}} \mid U_{\mathrm{A}}, \tilde{U}_{\mathrm{A} \oplus \mathrm{B}}\right)=H_{b}\left(p_{e} * p_{d}\right) .
$$

\section{APPENDIX B}

\section{DERIVATION OF (28)}

For the purpose of better illustration, we set $\Theta\left(\gamma_{\mathrm{R}, \mathrm{D}}\right)=$ $H_{b}\left(p_{d}\right), \Gamma\left(\gamma_{\mathrm{A}, \mathrm{R}}\right)=H_{b}\left(p_{e}\right), \Lambda\left(\gamma_{\mathrm{A}, \mathrm{R}}, \gamma_{\mathrm{R}, \mathrm{D}}\right)=H_{b}\left(p_{e} * p_{d}\right)$. The details of each components included in (28) are shown in (57)-(60). The coefficient " 2 " in (59) and (60) is due to the symmetry of the network topology. That is, the probabilities of $\mathcal{R}_{1}$ and $\mathcal{R}_{2}$ are equal and their impact on the outage probability is also equal.

\section{APPENDIX C}

DERIVATION OF (37), (43), AND (46)

The a priori LLR in (37) can be expressed as

$$
\begin{aligned}
L_{a}\left(x_{\mathrm{A}}^{k}\right) & =\ln \left(\frac{\sum_{i= \pm 1} \operatorname{Pr}\left(x_{\mathrm{A}}^{k}=1, x_{\mathrm{B}}^{k}=i \mid y_{\mathrm{R}, 1}^{k}\right)}{\sum_{i= \pm 1} \operatorname{Pr}\left(x_{\mathrm{A}}^{k}=-1, x_{\mathrm{B}}^{k}=i \mid y_{\mathrm{R}, 1}^{k}\right)}\right) \\
& =\ln \left(\frac{\sum_{i= \pm 1} \operatorname{Pr}\left(y_{\mathrm{R}, 1}^{k} \mid x_{\mathrm{A}}^{k}=1, x_{\mathrm{B}}^{k}=i\right) \operatorname{Pr}\left(x_{\mathrm{A}}^{k}=1, x_{\mathrm{B}}^{k}=i\right)}{\sum_{i= \pm 1} \operatorname{Pr}\left(y_{\mathrm{R}, 1}^{k} \mid x_{\mathrm{A}}^{k}=-1, x_{\mathrm{B}}^{k}=i\right) \operatorname{Pr}\left(x_{\mathrm{A}}^{k}=-1, x_{\mathrm{B}}^{k}=i\right)}\right) \\
& \stackrel{(a)}{=} \ln \left(\frac{\sum_{i= \pm 1} \operatorname{Pr}\left(y_{\mathrm{R}, 1}^{k} \mid x_{\mathrm{A}}^{k}=1, x_{\mathrm{B}}^{k}=i\right) \operatorname{Pr}\left(x_{\mathrm{B}}^{k}=i\right)}{\sum_{i= \pm 1} \operatorname{Pr}\left(y_{\mathrm{R}, 1}^{k} \mid x_{\mathrm{A}}^{k}=-1, x_{\mathrm{B}}^{k}=i\right) \operatorname{Pr}\left(x_{\mathrm{B}}^{k}=i\right)}\right)
\end{aligned}
$$

where $(a)$ takes into consideration of $x_{\mathrm{B}}^{k}$ only in the joint probabilities. In (61), $\operatorname{Pr}\left(y_{\mathrm{R}, 1}^{k} \mid x_{\mathrm{A}}^{k}=1, x_{\mathrm{B}}^{k}=i\right)$ and $\operatorname{Pr}\left(y_{\mathrm{R}, 1}^{k} \mid x_{\mathrm{A}}^{k}=\right.$ $-1, x_{\mathrm{B}}^{k}=i$ ) follow Gaussian distribution. Also, we know that $L_{e}\left(x_{\mathrm{B}}^{k}\right)=\ln \left(\operatorname{Pr}\left(x_{\mathrm{B}}^{k}=1\right) / \operatorname{Pr}\left(x_{\mathrm{B}}^{k}=-1\right)\right)$. After some manipulations, we can get the final expression of $L_{a}\left(x_{\mathrm{A}}^{k}\right)$ in (37).
In the derivation of (43), we first calculate the two probabilities, i.e., $\operatorname{Pr}\left(u_{\mathrm{A}}^{k}=0\right)$ and $\operatorname{Pr}\left(u_{\mathrm{A}}^{k}=1\right)$, and then take the $\ln$ operation on the ratio $\operatorname{Pr}\left(u_{\mathrm{A}}^{k}=0\right) / \operatorname{Pr}\left(u_{\mathrm{A}}^{k}=1\right)$.

$$
\begin{aligned}
\operatorname{Pr}\left(u_{\mathrm{A}}^{k}=0\right) & \stackrel{(a)}{=} \operatorname{Pr}\left(u_{\mathrm{A}}^{k}=0 \mid u_{\mathrm{B}}^{k}=0, u_{\mathrm{R}}^{k}=0\right) \operatorname{Pr}\left(u_{\mathrm{B}}^{k}=0, u_{\mathrm{R}}^{k}=0\right) \\
& +\operatorname{Pr}\left(u_{\mathrm{A}}^{k}=0 \mid u_{\mathrm{B}}^{k}=1, u_{\mathrm{R}}^{k}=1\right) \operatorname{Pr}\left(u_{\mathrm{B}}^{k}=1, u_{\mathrm{R}}^{k}=1\right) \\
& +\operatorname{Pr}\left(u_{\mathrm{A}}^{k}=0 \mid u_{\mathrm{B}}^{k}=0, u_{\mathrm{R}}^{k}=1\right) \operatorname{Pr}\left(u_{\mathrm{B}}^{k}=0, u_{\mathrm{R}}^{k}=1\right) \\
& +\operatorname{Pr}\left(u_{\mathrm{A}}^{k}=0 \mid u_{\mathrm{B}}^{k}=1, u_{\mathrm{R}}^{k}=0\right) \operatorname{Pr}\left(u_{\mathrm{B}}^{k}=1, u_{\mathrm{R}}^{k}=0\right) \\
& \stackrel{(b)}{=}\left(1-\hat{p}_{e}\right) \operatorname{Pr}\left(u_{\mathrm{B}}^{k}=0, u_{\mathrm{R}}^{k}=0\right) \\
& +\left(1-\hat{p}_{e}\right) \operatorname{Pr}\left(u_{\mathrm{B}}^{k}=1, u_{\mathrm{R}}^{k}=1\right) \\
& +\hat{p}_{e} \operatorname{Pr}\left(u_{\mathrm{B}}^{k}=0, u_{\mathrm{R}}^{k}=1\right)+\hat{p}_{e} \operatorname{Pr}\left(u_{\mathrm{B}}^{k}=1, u_{\mathrm{R}}^{k}=0\right) \\
& \stackrel{(c)}{=}\left(1-\hat{p}_{e}\right) \operatorname{Pr}\left(u_{\mathrm{B}}^{k}=0\right) \operatorname{Pr}\left(u_{\mathrm{R}}^{k}=0\right)\left(1-\hat{p}_{u}\right) \\
& +\left(1-\hat{p}_{e}\right) \operatorname{Pr}\left(u_{\mathrm{B}}^{k}=1\right) \operatorname{Pr}\left(u_{\mathrm{R}}^{k}=1\right) \hat{p}_{u} \\
& +\hat{p}_{e} \operatorname{Pr}\left(u_{\mathrm{B}}^{k}=0\right) \operatorname{Pr}\left(u_{\mathrm{R}}^{k}=1\right)\left(1-\hat{p}_{u}\right) \\
& +\hat{p}_{e} \operatorname{Pr}\left(u_{\mathrm{B}}^{k}=1\right) \operatorname{Pr}\left(u_{\mathrm{R}}^{k}=0\right) \hat{p}_{u},
\end{aligned}
$$

where $(a)$ follows Bayes' rules; $(b)$ is derived by using $\operatorname{Pr}\left(u_{\mathrm{A}}^{k}=0 \mid u_{\mathrm{B}}^{k}=0, u_{\mathrm{R}}^{k}=0\right)=\operatorname{Pr}\left(u_{\mathrm{A}}^{k}=0 \mid u_{\mathrm{B}}^{k}=1, u_{\mathrm{R}}^{k}=\right.$ $1)=\left(1-\hat{p}_{e}\right)$ and $\operatorname{Pr}\left(u_{\mathrm{A}}^{k}=0 \mid u_{\mathrm{B}}^{k}=0, u_{\mathrm{R}}^{k}=1\right)=\operatorname{Pr}\left(u_{\mathrm{A}}^{k}=\right.$ $\left.0 \mid u_{\mathrm{B}}^{k}=1, u_{\mathrm{R}}^{k}=0\right)=\hat{p}_{e}$; Note that we use the estimate of $p_{e}$ in the derivation instead of $p_{e} ;(c)$ follows Eqs. (8) and (9) in [6]. Similarly, we can get the expression for $\operatorname{Pr}\left(u_{\mathrm{A}}^{k}=1\right)$. Considering $L_{e}\left(u_{\mathrm{B}}^{k}\right)=\ln \left(\operatorname{Pr}\left(u_{\mathrm{B}}^{k}=0\right) / \operatorname{Pr}\left(u_{\mathrm{B}}^{k}=1\right)\right)$ and $L_{e}\left(u_{\mathrm{R}}^{k}\right)=\ln \left(\operatorname{Pr}\left(u_{\mathrm{R}}^{k}=0\right) / \operatorname{Pr}\left(u_{\mathrm{R}}^{k}=1\right)\right)$ and taking ln on $\operatorname{Pr}\left(u_{\mathrm{A}}^{k}=0\right) / \operatorname{Pr}\left(u_{\mathrm{A}}^{k}=1\right)$, we get the final expression of $L_{a}\left(u_{\mathrm{A}}^{k}\right)$ in (43).

The estimate of $p_{e}$ is shown in (63). Then, both numerator and denominator are divided by $\operatorname{Pr}\left(u_{\mathrm{A}}^{k}=1\right) \operatorname{Pr}\left(u_{\mathrm{B}}^{k}=\right.$ 1) $\operatorname{Pr}\left(u_{\mathrm{R}}^{k}=1\right)$. Considering $L_{p}\left(u_{\mathrm{A}}^{k}\right)=\ln \left(\operatorname{Pr}\left(u_{\mathrm{A}}^{k}=\right.\right.$ $\left.0) / \operatorname{Pr}\left(u_{\mathrm{A}}^{k}=1\right)\right), L_{p}\left(u_{\mathrm{B}}^{k}\right)=\ln \left(\operatorname{Pr}\left(u_{\mathrm{B}}^{k}=0\right) / \operatorname{Pr}\left(u_{\mathrm{B}}^{k}=1\right)\right)$, and $L_{p}\left(u_{\mathrm{R}}^{k}\right)=\ln \left(\operatorname{Pr}\left(u_{\mathrm{R}}^{k}=0\right) / \operatorname{Pr}\left(u_{\mathrm{R}}^{k}=1\right)\right)$, we get the part on the right side of summation in (46). After taking average over the information length $K$, we get the final expression, shown in (46).

\section{ACKNOWLEDGMENT}

The authors wish to thank the editor and the anonymous reviewers for their insightful comments.

\section{REFERENCES}

[1] X. Zhou, M. Cheng, X. He, and T. Matsumoto, "Exact and approximated outage probability analyses for decode-and-forward relaying system allowing intra-link errors," IEEE Trans. Wireless Commun., vol. 13, no. 12, pp. 7062-7071, Dec. 2014.

[2] Y. Zhao, R. Adve, and T. J. Lim, "Outage probability at arbitrary SNR with cooperative diversity," IEEE Commun. Lett., vol. 9, no. 8, pp. 700702, Aug. 2005.

[3] N. Beaulieu and J. Hu, "A closed-form expression for the outage probability of decode-and-forward relaying in dissimilar rayleigh fading channels," IEEE Commun. Lett., vol. 10, no. 12, pp. 813-815, Dec. 2006.

[4] P. Popovski and H. Yomo, "Physical network coding in two-way wireless relay channels," in Proc. of IEEE ICC, Jun. 2007, pp. 707-712.

[5] T. Koike-Akino, P. Popovski, and V. Tarokh, "Optimized constellations for two-way wireless relaying with physical network coding," IEEE Journal on Selected Areas in Communications, vol. 27, no. 5, pp. 773787, Jun. 2009.

[6] X. Zhou, P.-S. Lu, K. Anwar, and T. Matsumoto, "Correlated sources transmission in orthogonal multiple access relay channel: Theoretical analysis and performance evaluation," IEEE Trans. Wireless Commun., vol. 13 , no. 3, pp. 1424-1435, Mar. 2014. 
$\operatorname{Pr}\left\{\mathcal{S} \mid \mathcal{C}_{1}\right\} \operatorname{Pr}\left\{\mathcal{C}_{1}\right\}=\int \ldots \int p\left(\gamma_{\mathrm{A}, \mathrm{R}}\right) p\left(\gamma_{\mathrm{B}, \mathrm{R}}\right) p\left(\gamma_{\mathrm{R}, \mathrm{D}}\right) p\left(\gamma_{\mathrm{A}, \mathrm{D}}\right) p\left(\gamma_{\mathrm{B}, \mathrm{D}}\right) d \gamma_{\mathrm{A}, \mathrm{R}} d \gamma_{\mathrm{B}, \mathrm{R}} d \gamma_{\mathrm{R}, \mathrm{D}} d \gamma_{\mathrm{A}, \mathrm{D}} d \gamma_{\mathrm{B}, \mathrm{D}}$

$$
\begin{aligned}
& =\left[\int_{\Phi^{-1}(1)}^{\infty} p\left(\gamma_{\mathrm{B}, \mathrm{R}}\right) d \gamma_{\mathrm{B}, \mathrm{R}} \int_{\Phi^{-1}(1)\left(1+\gamma_{\mathrm{B}, \mathrm{R}}\right)}^{\infty} p\left(\gamma_{\mathrm{A}, \mathrm{R}}\right) d \gamma_{\mathrm{A}, \mathrm{R}}+\int_{\Phi^{-1}(1)}^{\left[\Phi^{-1}(1)+\Phi^{-1}(1) \Phi^{-1}(2)\right] /\left[1+\Phi^{-1}(1)\right]} p\left(\gamma_{\mathrm{A}, \mathrm{R}}\right) d \gamma_{\mathrm{A}, \mathrm{R}} \int_{\Phi^{-1}(2)-\gamma_{\mathrm{A}, \mathrm{R}}}^{\infty} p\left(\gamma_{\mathrm{B}, \mathrm{R}}\right) d \gamma_{\mathrm{B}, \mathrm{R}}\right. \\
& \left.+\int_{\left[\Phi^{-1}(1)+\Phi^{-1}(1) \Phi^{-1}(2)\right] /\left[1+\Phi^{-1}(1)\right]}^{\infty} p\left(\gamma_{\mathrm{A}, \mathrm{R}}\right) d \gamma_{\mathrm{A}, \mathrm{R}} \int_{\gamma_{\mathrm{A}, \mathrm{R}} / \Phi^{-1}(1)-1}^{\infty} p\left(\gamma_{\mathrm{B}, \mathrm{R}}\right) d \gamma_{\mathrm{B}, \mathrm{R}}\right] \\
& \times\left[\int_{\Phi^{-1}(1)}^{\infty} p\left(\gamma_{\mathrm{R}, \mathrm{D}}\right) d \gamma_{\mathrm{R}, \mathrm{D}} \int_{\Phi^{-1}(0)}^{\Phi^{-1}(1)} p\left(\gamma_{\mathrm{A}, \mathrm{D}}\right) d \gamma_{\mathrm{A}, \mathrm{D}} \int_{\Phi^{-1}(1)-\gamma_{\mathrm{A}, \mathrm{D}}}^{\infty} p\left(\gamma_{\mathrm{B}, \mathrm{D}}\right) d \gamma_{\mathrm{B}, \mathrm{D}}\right. \\
& \left.+\int_{\Phi^{-1}(1)}^{\infty} p\left(\gamma_{\mathrm{R}, \mathrm{D}}\right) d \gamma_{\mathrm{R}, \mathrm{D}} \int_{\Phi^{-1}(1)}^{\infty} p\left(\gamma_{\mathrm{A}, \mathrm{D}}\right) d \gamma_{\mathrm{A}, \mathrm{D}} \int_{0}^{\infty} p\left(\gamma_{\mathrm{B}, \mathrm{D}}\right) d \gamma_{\mathrm{B}, \mathrm{D}}\right]
\end{aligned}
$$

$\operatorname{Pr}\left\{\mathcal{S} \mid \mathcal{C}_{2}\right\} \operatorname{Pr}\left\{\mathcal{C}_{2}\right\}=\int \ldots \int p\left(\gamma_{\mathrm{A}, \mathrm{R}}\right) p\left(\gamma_{\mathrm{B}, \mathrm{R}}\right) p\left(\gamma_{\mathrm{R}, \mathrm{D}}\right) p\left(\gamma_{\mathrm{A}, \mathrm{D}}\right) p\left(\gamma_{\mathrm{B}, \mathrm{D}}\right) d \gamma_{\mathrm{A}, \mathrm{R}} d \gamma_{\mathrm{B}, \mathrm{R}} d \gamma_{\mathrm{R}, \mathrm{D}} d \gamma_{\mathrm{A}, \mathrm{D}} d \gamma_{\mathrm{B}, \mathrm{D}}$

$$
\begin{aligned}
& =\left[\int_{\Phi^{-1}(1)}^{\infty} p\left(\gamma_{\mathrm{B}, \mathrm{R}}\right) d \gamma_{\mathrm{B}, \mathrm{R}} \int_{\Phi^{-1}(1)\left(1+\gamma_{\mathrm{B}, \mathrm{R}}\right)}^{\infty} p\left(\gamma_{\mathrm{A}, \mathrm{R}}\right) d \gamma_{\mathrm{A}, \mathrm{R}}+\int_{\Phi^{-1}(1)}^{\left[\Phi^{-1}(1)+\Phi^{-1}(1) \Phi^{-1}(2)\right] /\left[1+\Phi^{-1}(1)\right]} p\left(\gamma_{\mathrm{A}, \mathrm{R}}\right) d \gamma_{\mathrm{A}, \mathrm{R}} \int_{\Phi^{-1}(2)-\gamma_{\mathrm{A}, \mathrm{R}}}^{\infty} p\left(\gamma_{\mathrm{B}, \mathrm{R}}\right) d \gamma_{\mathrm{B}, \mathrm{R}}\right. \\
& \left.+\int_{\left[\Phi^{-1}(1)+\Phi^{-1}(1) \Phi^{-1}(2)\right] /\left[1+\Phi^{-1}(1)\right]}^{\infty} p\left(\gamma_{\mathrm{A}, \mathrm{R}}\right) d \gamma_{\mathrm{A}, \mathrm{R}} \int_{\gamma_{\mathrm{A}, \mathrm{R}} / \Phi^{-1}(1)-1}^{\infty} p\left(\gamma_{\mathrm{B}, \mathrm{R}}\right) d \gamma_{\mathrm{B}, \mathrm{R}}\right] \\
& \times\left[\int_{\Phi^{-1}(0)}^{\Phi^{-1}(1)} p\left(\gamma_{\mathrm{R}, \mathrm{D}}\right) d \gamma_{\mathrm{R}, \mathrm{D}} \int_{\Phi^{-1}\left[\Theta\left(\gamma_{\mathrm{R}, \mathrm{D}}\right)\right]}^{\Phi^{-1}(1)} p\left(\gamma_{\mathrm{A}, \mathrm{D}}\right) d \gamma_{\mathrm{A}, \mathrm{D}} \int_{\Phi^{-1}\left[1+\Theta\left(\gamma_{\mathrm{R}, \mathrm{D}}\right)\right]-\gamma_{\mathrm{A}, \mathrm{D}}}^{\infty} p\left(\gamma_{\mathrm{B}, \mathrm{D}}\right) d \gamma_{\mathrm{B}, \mathrm{D}}\right. \\
& \left.+\int_{\Phi^{-1}(0)}^{\Phi^{-1}(1)} p\left(\gamma_{\mathrm{R}, \mathrm{D}}\right) d \gamma_{\mathrm{R}, \mathrm{D}} \int_{\Phi^{-1}(1)}^{\infty} p\left(\gamma_{\mathrm{A}, \mathrm{D}}\right) d \gamma_{\mathrm{A}, \mathrm{D}} \int_{\Phi^{-1}\left[\Theta\left(\gamma_{\mathrm{R}, \mathrm{D}}\right)\right]}^{\infty} p\left(\gamma_{\mathrm{B}, \mathrm{D}}\right) d \gamma_{\mathrm{B}, \mathrm{D}}\right]
\end{aligned}
$$

$\operatorname{Pr}\left\{\mathcal{S} \mid \mathcal{C}_{3}\right\} \operatorname{Pr}\left\{\mathcal{C}_{3}\right\}=\int \ldots \int p\left(\gamma_{\mathrm{A}, \mathrm{R}}\right) p\left(\gamma_{\mathrm{B}, \mathrm{R}}\right) p\left(\gamma_{\mathrm{R}, \mathrm{D}}\right) p\left(\gamma_{\mathrm{A}, \mathrm{D}}\right) p\left(\gamma_{\mathrm{B}, \mathrm{D}}\right) d \gamma_{\mathrm{A}, \mathrm{R}} d \gamma_{\mathrm{B}, \mathrm{R}} d \gamma_{\mathrm{R}, \mathrm{D}} d \gamma_{\mathrm{A}, \mathrm{D}} d \gamma_{\mathrm{B}, \mathrm{D}}$

$$
\begin{aligned}
& =2 \times \int_{\Phi^{-1}(1)}^{\infty} p\left(\gamma_{\mathrm{B}, \mathrm{R}}\right) d \gamma_{\mathrm{B}, \mathrm{R}} \int_{0}^{\Phi^{-1}(1)\left(1+\gamma_{\mathrm{B}, \mathrm{R}}\right)} p\left(\gamma_{\mathrm{A}, \mathrm{R}}\right) d \gamma_{\mathrm{A}, \mathrm{R}} \\
& \times\left[\int_{\Phi^{-1}(1)}^{\infty} p\left(\gamma_{\mathrm{R}, \mathrm{D}}\right) d \gamma_{\mathrm{R}, \mathrm{D}} \int_{\Phi^{-1}\left[\Gamma\left(\gamma_{\mathrm{A}, \mathrm{R}}\right)\right]}^{\Phi^{-1}(1)} p\left(\gamma_{\mathrm{A}, \mathrm{D}}\right) d \gamma_{\mathrm{A}, \mathrm{D}} \int_{\Phi^{-1}\left[1+\Gamma\left(\gamma_{\mathrm{A}, \mathrm{R}}\right)\right]-\gamma_{\mathrm{A}, \mathrm{D}}}^{\infty} p\left(\gamma_{\mathrm{B}, \mathrm{D}}\right) d \gamma_{\mathrm{B}, \mathrm{D}}\right. \\
& \left.+\int_{\Phi^{-1}(1)}^{\infty} p\left(\gamma_{\mathrm{R}, \mathrm{D}}\right) d \gamma_{\mathrm{R}, \mathrm{D}} \int_{\Phi^{-1}(1)}^{\infty} p\left(\gamma_{\mathrm{A}, \mathrm{D}}\right) d \gamma_{\mathrm{A}, \mathrm{D}} \int_{\Phi^{-1}\left[\Gamma\left(\gamma_{\mathrm{A}, \mathrm{R}}\right)\right]}^{\infty} p\left(\gamma_{\mathrm{B}, \mathrm{D}}\right) d \gamma_{\mathrm{B}, \mathrm{D}}\right],
\end{aligned}
$$

$\operatorname{Pr}\left\{\mathcal{S} \mid \mathcal{C}_{4}\right\} \operatorname{Pr}\left\{\mathcal{C}_{4}\right\}=\int \ldots \int p\left(\gamma_{\mathrm{A}, \mathrm{R}}\right) p\left(\gamma_{\mathrm{B}, \mathrm{R}}\right) p\left(\gamma_{\mathrm{R}, \mathrm{D}}\right) p\left(\gamma_{\mathrm{A}, \mathrm{D}}\right) p\left(\gamma_{\mathrm{B}, \mathrm{D}}\right) d \gamma_{\mathrm{A}, \mathrm{R}} d \gamma_{\mathrm{B}, \mathrm{R}} d \gamma_{\mathrm{R}, \mathrm{D}} d \gamma_{\mathrm{A}, \mathrm{D}} d \gamma_{\mathrm{B}, \mathrm{D}}$

$$
\begin{aligned}
& =2 \times \int_{\Phi^{-1}(1)}^{\infty} p\left(\gamma_{\mathrm{B}, \mathrm{R}}\right) d \gamma_{\mathrm{B}, \mathrm{R}} \int_{0}^{\Phi^{-1}(1)\left(1+\gamma_{\mathrm{B}, \mathrm{R}}\right)} p\left(\gamma_{\mathrm{A}, \mathrm{R}}\right) d \gamma_{\mathrm{A}, \mathrm{R}} \\
& \times\left[\int_{\Phi^{-1}(0)}^{\Phi^{-1}(1)} p\left(\gamma_{\mathrm{R}, \mathrm{D}}\right) d \gamma_{\mathrm{R}, \mathrm{D}} \int_{\Phi^{-1}\left[\Lambda\left(\gamma_{\mathrm{A}, \mathrm{R}}, \gamma_{\mathrm{R}, \mathrm{D}}\right)\right]}^{\Phi^{-1}(1)} p\left(\gamma_{\mathrm{A}, \mathrm{D}}\right) d \gamma_{\mathrm{A}, \mathrm{D}} \int_{\Phi^{-1}\left[1+\Lambda\left(\gamma_{\mathrm{A}, \mathrm{R}}, \gamma_{\mathrm{R}, \mathrm{D}}\right)\right]-\gamma_{\mathrm{A}, \mathrm{D}}}^{\infty} p\left(\gamma_{\mathrm{B}, \mathrm{D}}\right) d \gamma_{\mathrm{B}, \mathrm{D}}\right. \\
& \left.+\int_{\Phi^{-1}(0)}^{\Phi^{-1}(1)} p\left(\gamma_{\mathrm{R}, \mathrm{D}}\right) d \gamma_{\mathrm{R}, \mathrm{D}} \int_{\Phi^{-1}(1)}^{\infty} p\left(\gamma_{\mathrm{A}, \mathrm{D}}\right) d \gamma_{\mathrm{A}, \mathrm{D}} \int_{\Phi^{-1}\left[\Lambda\left(\gamma_{\mathrm{A}, \mathrm{R}}, \gamma_{\mathrm{R}, \mathrm{D}}\right)\right]}^{\infty} p\left(\gamma_{\mathrm{B}, \mathrm{D}}\right) d \gamma_{\mathrm{B}, \mathrm{D}}\right]
\end{aligned}
$$




$$
\begin{aligned}
\hat{p}_{e} & =\operatorname{Pr}\left(u_{\mathrm{A}}^{k}=0\right) \operatorname{Pr}\left(u_{\mathrm{B}}^{k}=0\right) \operatorname{Pr}\left(u_{\mathrm{R}}^{k}=1\right)+\operatorname{Pr}\left(u_{\mathrm{A}}^{k}=0\right) \operatorname{Pr}\left(u_{\mathrm{B}}^{k}=1\right) \operatorname{Pr}\left(u_{\mathrm{R}}^{k}=0\right) \\
& +\operatorname{Pr}\left(u_{\mathrm{A}}^{k}=1\right) \operatorname{Pr}\left(u_{\mathrm{B}}^{k}=0\right) \operatorname{Pr}\left(u_{\mathrm{R}}^{k}=0\right)+\operatorname{Pr}\left(u_{\mathrm{A}}^{k}=1\right) \operatorname{Pr}\left(u_{\mathrm{B}}^{k}=1\right) \operatorname{Pr}\left(u_{\mathrm{R}}^{k}=1\right) \\
& =\frac{\operatorname{Pr}\left(u_{\mathrm{A}}^{k}=0\right) \operatorname{Pr}\left(u_{\mathrm{B}}^{k}=0\right) \operatorname{Pr}\left(u_{\mathrm{R}}^{k}=1\right)+\operatorname{Pr}\left(u_{\mathrm{A}}^{k}=0\right) \operatorname{Pr}\left(u_{\mathrm{B}}^{k}=1\right) \operatorname{Pr}\left(u_{\mathrm{R}}^{k}=0\right)}{\left[\operatorname{Pr}\left(u_{\mathrm{A}}^{k}=0\right)+\operatorname{Pr}\left(u_{\mathrm{A}}^{k}=1\right)\right]\left[\operatorname{Pr}\left(u_{\mathrm{B}}^{k}=0\right)+\operatorname{Pr}\left(u_{\mathrm{B}}^{k}=1\right)\right]\left[\operatorname{Pr}\left(u_{\mathrm{R}}^{k}=0\right)+\operatorname{Pr}\left(u_{\mathrm{R}}^{k}=1\right)\right]} \\
& +\frac{\operatorname{Pr}\left(u_{\mathrm{A}}^{k}=1\right) \operatorname{Pr}\left(u_{\mathrm{B}}^{k}=0\right) \operatorname{Pr}\left(u_{\mathrm{R}}^{k}=0\right)+\operatorname{Pr}\left(u_{\mathrm{A}}^{k}=1\right) \operatorname{Pr}\left(u_{\mathrm{B}}^{k}=1\right) \operatorname{Pr}\left(u_{\mathrm{R}}^{k}=1\right)}{\left[\operatorname{Pr}\left(u_{\mathrm{A}}^{k}=0\right)+\operatorname{Pr}\left(u_{\mathrm{A}}^{k}=1\right)\right]\left[\operatorname{Pr}\left(u_{\mathrm{B}}^{k}=0\right)+\operatorname{Pr}\left(u_{\mathrm{B}}^{k}=1\right)\right]\left[\operatorname{Pr}\left(u_{\mathrm{R}}^{k}=0\right)+\operatorname{Pr}\left(u_{\mathrm{R}}^{k}=1\right)\right]}
\end{aligned}
$$

[7] D. H. Woldegebreal and H. Karl, "Multiple-access relay channel with network coding and non-ideal source-relay channels," in Proc. of ISWCS, Oct. 2007, pp. 732-736.

[8] P.-S. Lu, X. Zhou, and T. Matsumoto, "Outage probabilities of orthogonal multiple-access relaying techniques with imperfect source-relay links," IEEE Trans. Wireless Commun., vol. 14, no. 4, pp. 2269-2280, Apr. 2015.

[9] Y. Li, G. Song, and L. Wang, "Design of joint network-low density parity check codes based on the EXIT charts," IEEE Commun. Lett., vol. 13, no. 8, pp. 600-602, Aug. 2009.

[10] P.-S. Lu, X. Zhou, K. Anwar, and T. Matsumoto, "Joint adaptive network-channel coding for energy-efficient multiple-access relaying," IEEE Trans. Veh. Technol., vol. 63, no. 5, pp. 2298-2305, Jun. 2014.

[11] C. Hausl and P. Dupraz, "Joint network-channel coding for the multipleaccess relay channel," in proc. of IEEE Communications Society on Sensor and Ad Hoc Communications and Networks, vol. 3, Sep 2006, pp. 817-822.

[12] E. Paolini, C. Stefanovic, G. Liva, and P. Popovski, "Coded random access: applying codes on graphs to design random access protocols," IEEE Commun. Mag., vol. 53, no. 6, pp. 144-150, Jun. 2015.

[13] Z. Zhang, C. Xu, and L. Ping, "Coded random access with distributed power control and multiple-packet reception," IEEE Wireless Commun. Lett., vol. 4, no. 2, pp. 117-120, Apr. 2015.

[14] J. He, I. Hussain, M. Juntti, and T. Matsumoto, "Transmission of correlated sources over non-orthogonal Gaussian MACs," in Proc. of IEEE ICC Workshops, May 2016, pp. 534-539.

[15] K. Anwar and T. Matsumoto, "Iterative spatial demapping for two correlated sources with power control over fading MAC," in Proc. of IEEE VTC, May 2012, pp. 1-7.

[16] J. He, I. Hussain, V. Tervo, M. Juntti, and T. Matsumoto, "Performance analysis for transmission of correlated sources over non-orthogonal MARCs," in Proc. of International Symposium on Turbo Codes and Iterative Information Processing (ISTC), Sept 2016, pp. 66-70.

[17] L. Ping, L. Liu, K. Wu, and W. K. Leung, "Interleave division multipleaccess," IEEE Trans. Wireless Commun., vol. 5, no. 4, pp. 938-947, Apr. 2006.

[18] J. Tong and L. Ping, "Performance analysis of superposition coded modulation," Physical Communication, vol. 3, no. 3, pp. 147 - 155, 2010.

[19] P. Chen, S. C. Liew, and L. Shi, "Bandwidth-efficient coded modulation schemes for physical-layer network coding with high-order modulations," IEEE Trans. Commun., vol. 65, no. 1, pp. 147-160, Jan 2017.

[20] T. Cover and A. E. Gamal, "Capacity theorems for the relay channel," IEEE Trans. Inf. Theory, vol. 25, no. 5, pp. 572-584, Sep 1979.

[21] J. N. Laneman and G. W. Wornell, "Distributed space-time-coded protocols for exploiting cooperative diversity in wireless networks," IEEE Trans. Inf. Theory, vol. 49, no. 10, pp. 2415-2425, Oct 2003.

[22] J. N. Laneman, D. N. C. Tse, and G. W. Wornell, "Cooperative diversity in wireless networks: Efficient protocols and outage behavior," IEEE Trans. Inf. Theory, vol. 50, no. 12, pp. 3062-3080, Dec 2004.

[23] G. Kramer, M. Gastpar, and P. Gupta, "Cooperative strategies and capacity theorems for relay networks," IEEE Trans. Inf. Theory, vol. 51, no. 9, pp. 3037-3063, Sep 2005.

[24] A. Bletsas, H. Shin, and M. Z. Win, "Cooperative communications with outage-optimal opportunistic relaying," IEEE Trans. Wireless Commun., vol. 6, no. 9, pp. 3450-3460, September 2007.

[25] 3GPP Technical Report 36.814. V2.0.1., "Further advancements for EUTRA physical layer aspects." Mar 2010.

[26] D. C. Gonzalez, A. Wolf, L. L. Mendes, J. C. S. S. Filho, and G. Fettweis, "An efficient power allocation scheme for multirelay systems with lossy intra-links," IEEE Trans. Commun., vol. PP, no. 99, pp. 1-1, 2017.

[27] A. El Gamal and Y.-H. Kim, Network information theory. Cambridge university press, 2011.
[28] X. Zhou, X. He, M. Juntti, and T. Matsumoto, "Outage probability of correlated binary source transmission over fading multiple access channels," in Proc. of IEEE SPAWC, Jun. 2015, pp. 96-100.

[29] R. Narasimhan, "Individual outage rate regions for fading multiple access channels," in in Proc. of IEEE ISIT, Jun. 2007, pp. 1571-1575.

[30] G. Ungerboeck, "Channel coding with multilevel/phase signals," IEEE Trans. Inf. Theory, vol. 28, no. 1, pp. 55-67, Jan 1982

[31] X. Zhou, M. Cheng, K. Anwar, and T. Matsumoto, "Distributed joint source-channel coding for relay systems exploiting source-relay correlation and source memory," EURASIP Journal on Wireless Communications and Networking, vol. 2012, no. 1, p. 260, 2012.

[32] L. You, S. C. Liew, and L. Lu, "Network-coded multiple access II: Toward real-time operation with improved performance," IEEE J. Sel. Areas Commun., vol. 33, no. 2, pp. 264-280, Feb. 2015.

[33] L. Bahl, J. Cocke, F. Jelinek, and J. Raviv, "Optimal decoding of linear codes for minimizing symbol error rate," IEEE Trans. Inf. Theory, vol. 20, no. 2, pp. 284-287, Mar 1974.

[34] K. Anwar and T. Matsumoto, "Accumulator-assisted distributed turbo codes for relay systems exploiting source-relay correlation," IEEE Commun. Lett., vol. 16, no. 7, pp. 1114-1117, Jul. 2012.

[35] O. Y. Takeshita and D. J. Costello, "New deterministic interleaver designs for turbo codes," IEEE Trans. Inf. Theory, vol. 46, no. 6, pp. 1988-2006, Sep. 2000.

[36] R. Youssef and A. G. i. Amat, "Distributed serially concatenated codes for multi-source cooperative relay networks," IEEE Trans. Wireless Commun., vol. 10, no. 1, pp. 253-263, Jan. 2011. 